\title{
Estimation of Model Parameters, for Torsional Vibration Analysis of a Turbo-Generator Unit with Reference to Mosul Gas-Turbine Station
}

\author{
Prof. Dr. S. M. J. Ali $\quad$ Dr. Z. Y. Mohammad $\quad$ Dr. F. Q. Yahya \\ Mechanical Engineering Department / College of Engineering / University of Mosul
}

Abstract

In the design stage or analysis of any dynamical system a detailed or comprehensive model is essentially required. In this work, different parts and components that are contained in the model of a turbo-generator unit (T.G) for torsional vibration analysis are considered and the governing equations of which are presented and developed to estimate their respective parameters. These parts and components are mainly compressor seventeen stages and blades, turbine two stages and blades, reduction gear system with the safety shaft, the rotor of the generator, the exciter and the fluid film bearings on which the whole system is supported. The data upon which the system model is built are referred to Mosul gas turbine station units. The estimated parameters are those related to rotational inertia, damping and stiffness effects of the different components in the system. A detailed model of the system should be useful for the purpose of torsional vibrational during rotation with normal steady loading or under severe loading conditions utilizing a block diagram via Matlab. The system eigen values natural frequencies (critical speeds) and mode shapes are determined.

Keywords: Torsional vibrations, stiffness, damping, turbo-generator unit, natural frequency

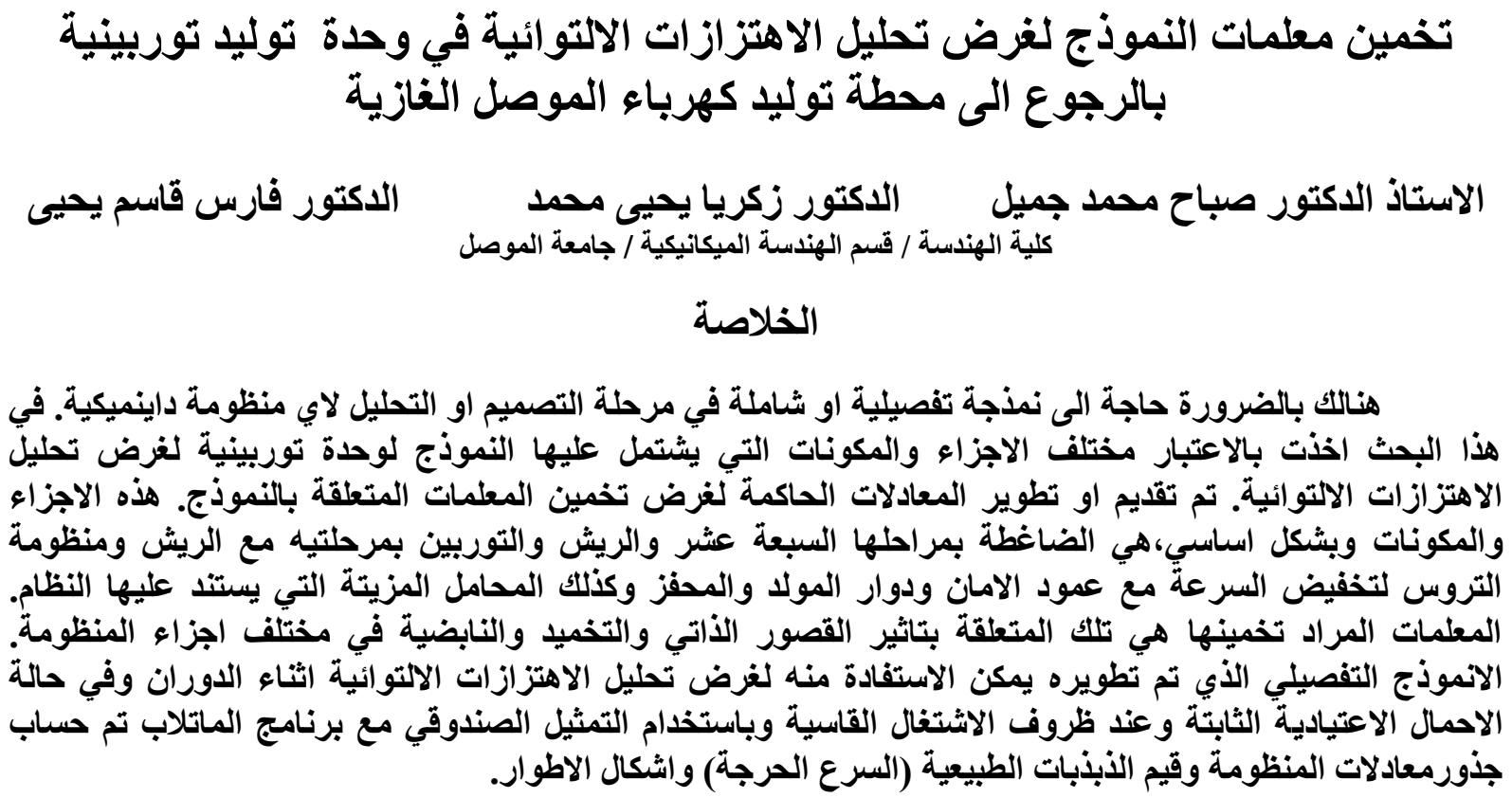

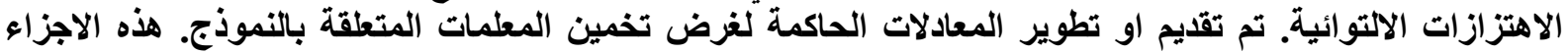

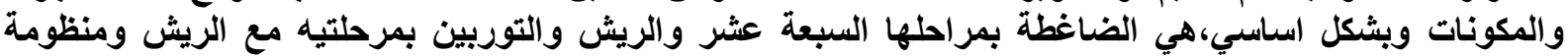

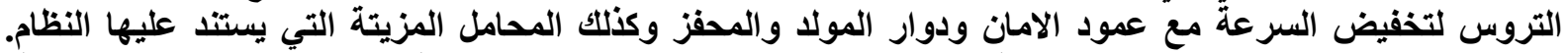

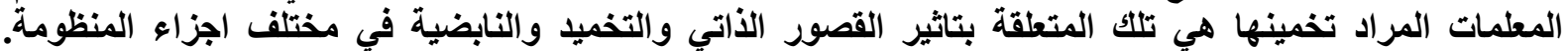

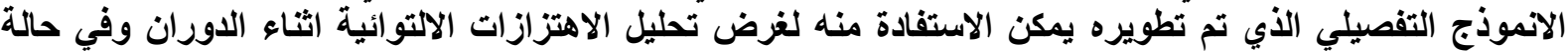

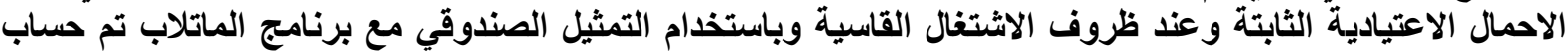

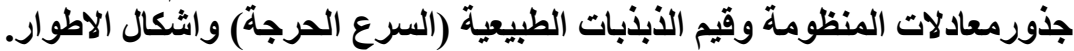



Al-Rafidain Engineering
Vol.23
No. 2
April 2015

\section{Introduction}

The main motivation of this work is the need for accurate model of a turbo-generator unit in gas turbine power stations. These models are essentially needed for transient load studies or in the analysis of the dynamic behavior of a turbo-generator for torsional vibration analysis in the unit under severe loading conditions (i.e. electric network disturbances). The generating units in Mosul gas turbine station has undergone several problems on a number of occasions due to running with this kind of loading conditions represented by electrical faults.

Building of a dynamical model is the first step in the analysis of a torsional vibration problems. In the field of machinery dynamics, equivalent inertias, linear torsional springs and linearized damping coefficient have been used in order to construct a lumped or discrete mass model.

\section{Evaluation of Dynamic Coefficients}

A major task in this work is to evaluate the necessary stiffness and damping coefficients that are needed in constructing a comprehensive dynamic model of a turbo-generator unit.

Torsional damping is defined as a critical parameter, which cannot, in general, be reliably predicted by analytical or experimental means. Most of the individual damping mechanisms are complex and are not presently predictable at the design step [1].

There are only small damping effects in some of the rotating assembly. These are considered as negligible, such as oil film damping, gear sliding friction damping and fluid damping. Significant damping such as the material damping, electrical damping, and gear damping, may be accounted for.

The analysis, including, station-to-ground viscous damping has been formulated by a number of researchers in the past and recently $[2,3,4]$.

Damping is the most critical parameter which is difficult to estimate. Viscous damping results from the shearing of a fluid (lubricant) in the gap between the moving parts are considered to be a linear function of relative velocity [5].

Damping is often a non-linear phenomena, it has been standard practice to linearize the description formulae as in gear damping, bearing oil film damping and electrical damping. On the other hand, when the non-linear fluid damping is linearized it employs an equivalent viscous damping [6].

The purpose of this paper is to built a complete torsional vibration model of a turbogenerator unit for Mosul gas turbine station in conjunction with the electrical network. This type of model should be useful in investigating and analyzing the dynamic behavior of a turbo-generator unit under normal and severe loading conditions or sudden electrical network disturbances which causes the consequences of the mechanical failures in the couplings and rotating segments. The rotational critical speeds of the unit may also be predicted.

\section{Model Description and Mathematical Formulation}

Introducing linear stiffness and viscous damping into a dynamical system results the following vector-matrix equation of motion:

$$
(\mathrm{J})[\ddot{\theta}]+(\mathrm{C})[\dot{\theta}]+(\mathrm{K})[\theta]=[\mathrm{T}]
$$

$\theta$ is the angular perturbation vector of the segment lumped masses and the blade masses. 
Describing the system dynamics in a state-space form the above equation may be reformulated to be:

$$
[\dot{\mathrm{X}}]=[\mathrm{A}][\mathrm{X}]+[\mathrm{B}][\mathrm{U}]
$$

Here, $[\mathrm{X}]$ is the state vector comprises the deviation angular positions and velocities, $[\mathrm{U}]$ is the input vector, matrices $[\mathrm{A}]$ and $[\mathrm{B}]$ are the proper system and input matrices respectively.

The homogenous case of the above state space-equation is:

$$
[\dot{\mathrm{X}}]=[\mathrm{A}][\mathrm{X}]
$$

may be used to determine the system eigen values and eigen vectors from the determinant:

$$
[\lambda \mathrm{I}-\mathrm{A}]=0
$$

Here $\mathrm{A}$ is the system matrix which contain elements related to the inertia, damping and stiffness matrices system.

In this system, the turbo-generator unit comprises a gas turbine of open cycle type with single shaft arrangement that contains 17-stage axial compressor and 2-stage axial turbine with multiple combustors. These stages are connected to the reduction gear system by a gear coupling and two rigid flanged couplings. The gear system consists of a pair of involute spur gears. They are connected to the AC generator (alternator) by a highly flexible spline shaft, named as quill shaft giving a mechanically limited safety device of the unit under overload conditions. The quill shaft is connected to a rigid flanged coupling. The operating speed of rotation of the compressor-turbine set is $5100 \mathrm{rpm}$, while that of the exciter-generator set is $3000 \mathrm{rpm}$. The whole system is illustrated in figure (1).

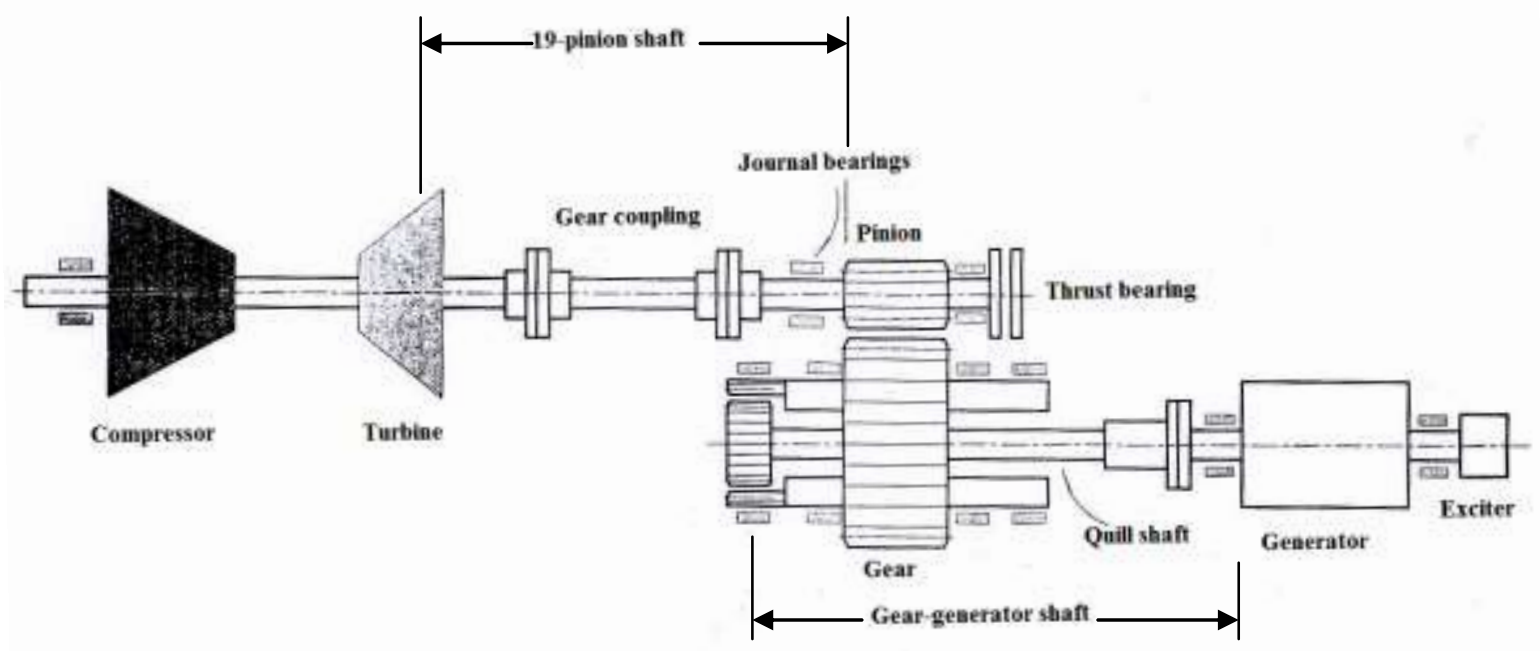

Figure (1): The turbo-generator unit (system studied), drawing not to scale dampers.

The system model may be represented by a collection of lumped masses, springs and

The governing differential equations of motion for a shaft segment and a jth blade of compressor and turbine, figure (2), can be written in terms of angular variation about the 
steady state operating angular deflection and their derivatives to give the effective angular velocities and accelerations. They are as follows:

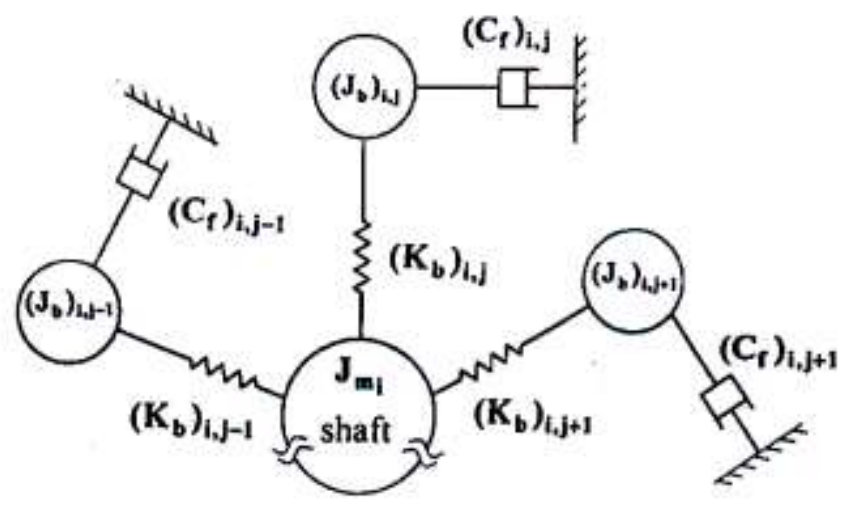

Figure (2): Rotational inertia-damper-spring model of tuned compressor and turbine bladed disk, $\left(i=1\right.$ to no. of stages $=19, j=1$ to no. of blades in each stage $=n_{b}$ )

$\mathrm{J}_{\mathrm{m}_{\mathrm{i}}} \ddot{\theta}_{\mathrm{i}}=-\mathrm{K}_{\mathrm{S}_{\mathrm{i}}}\left(\theta_{\mathrm{i}}-\theta_{\mathrm{i}+1}\right)-\mathrm{C}_{\mathrm{S}_{\mathrm{i}}}\left(\dot{\theta}_{\mathrm{i}}-\dot{\theta}_{\mathrm{i}+1}\right)-\mathrm{n}_{\mathrm{b}_{\mathrm{i}}} \mathrm{K}_{\mathrm{b}_{\mathrm{i}}}\left(\theta_{\mathrm{i}}-\theta_{\mathrm{b}_{\mathrm{i}}}\right)-\mathrm{C}_{\mathrm{B}_{\mathrm{i}}} \dot{\theta}_{\mathrm{i}}$

$[\mathrm{i}=1]$

$\mathrm{J}_{\mathrm{b}_{\mathrm{i}}} \ddot{\theta}_{\mathrm{b}_{\mathrm{i}}}=-\mathrm{K}_{\mathrm{b}_{\mathrm{i}}}\left(\theta_{\mathrm{b}_{\mathrm{i}}}-\theta_{\mathrm{i}}\right)-\mathrm{C}_{\mathrm{f}_{\mathrm{i}}} \dot{\theta}_{\mathrm{b}_{\mathrm{i}}}$

(Including equations 3, 5, 7, 9, 11, 13, 15, 17, 19, 21, 23, 25, 27, 29, 31, 33, 35, 37, 39)

$$
\begin{aligned}
& \mathrm{J}_{\mathrm{m}_{\mathrm{i}+1}} \ddot{\theta}_{\mathrm{i}+1}=-\mathrm{K}_{\mathrm{S}_{\mathrm{i}}}\left(\theta_{\mathrm{i}+1}-\theta_{\mathrm{i}}\right)-\mathrm{K}_{\mathrm{S}_{\mathrm{i}+1}}\left(\theta_{\mathrm{i}+1}-\theta_{\mathrm{i}+2}\right)-\mathrm{C}_{\mathrm{S}_{\mathrm{i}}}\left(\dot{\theta}_{\mathrm{i}+1}-\dot{\theta}_{\mathrm{i}}\right) \\
& -\mathrm{C}_{\mathrm{S}_{\mathrm{i}+1}}\left(\dot{\theta}_{\mathrm{i}+1}-\dot{\theta}_{\mathrm{i}+2}\right)-\mathrm{n}_{\mathrm{b}_{\mathrm{i}+1}} \mathrm{~K}_{\mathrm{b}_{\mathrm{i}+1}}\left(\theta_{\mathrm{i}+1}-\theta_{\mathrm{b}_{\mathrm{i}+1}}\right)
\end{aligned}
$$

(Including equations 4, 6, 8, 10, 12, 14, 16, 18, 20, 22, 24, 26, 28, 30, 32, 34, 36)

$$
\begin{aligned}
& \mathrm{J}_{\mathrm{m}_{\mathrm{i}+1}} \ddot{\theta}_{\mathrm{i}+1}=-\mathrm{K}_{\mathrm{S}_{\mathrm{i}}}\left(\theta_{\mathrm{i}+1}-\theta_{\mathrm{i}}\right)-\mathrm{K}_{\mathrm{S}_{\mathrm{i}+1}}\left(\theta_{\mathrm{i}+1}-\theta_{\mathrm{i}+2}\right)-\mathrm{C}_{\mathrm{S}_{\mathrm{i}}}\left(\theta_{\mathrm{i}+1}-\theta_{\mathrm{i}}\right) \\
& -\mathrm{C}_{\mathrm{S}_{\mathrm{i}+1}}\left(\dot{\theta}_{\mathrm{i}+1}-\dot{\theta}_{\mathrm{i}+2}\right)-\mathrm{n}_{\mathrm{b}_{\mathrm{i}+1}} \mathrm{~K}_{\mathrm{b}_{\mathrm{i}+1}}\left(\theta_{\mathrm{i}+1}-\theta_{\mathrm{b}_{\mathrm{i}+1}}\right)-\mathrm{C}_{\mathrm{B}_{\mathrm{i}}} \dot{\theta}_{\mathrm{i}} \quad[\mathrm{i}=18] \\
& \mathrm{J}_{\mathrm{m}_{\mathrm{P}}} \ddot{\theta}_{\mathrm{p}}=-\mathrm{K}_{\mathrm{S}_{19}}\left(\theta_{\mathrm{P}}-\theta_{19}\right)-\mathrm{C}_{\mathrm{S}_{19}}\left(\dot{\theta}_{\mathrm{P}}-\dot{\theta}_{\mathrm{g}}\right)-\left(\mathrm{C}_{\mathrm{B}_{3}}+\mathrm{C}_{\mathrm{B}_{4}}\right) \dot{\theta}_{\mathrm{P}}-\mathrm{C}_{\mathrm{F}_{\mathrm{P}}}\left(\dot{\theta}_{\mathrm{P}}-\dot{\theta}_{\mathrm{g}}\right)-\mathrm{T}_{\mathrm{d}} \\
& \mathrm{J}_{\mathrm{mg}} \ddot{\theta}_{\mathrm{g}}=-\mathrm{K}_{\mathrm{S}_{20}}\left(\theta_{\mathrm{g}}-\theta_{20}\right)-\mathrm{C}_{\mathrm{S}_{20}}\left(\dot{\theta}_{\mathrm{g}}-\dot{\theta}_{20}\right)+\mathrm{C}_{\mathrm{Fg}}\left(\dot{\theta}_{\mathrm{g}}-\dot{\theta}_{\mathrm{P}}\right) \\
& -\left(\mathrm{C}_{\mathrm{B}_{5}}+\mathrm{C}_{\mathrm{B}_{6}}+\mathrm{C}_{\mathrm{B}_{7}}+\mathrm{C}_{\mathrm{B}_{8}}\right) \dot{\theta}_{\mathrm{g}}+\mathrm{SR} . \mathrm{T}_{\mathrm{d}} \\
& \mathrm{J}_{\mathrm{m}_{20}} \ddot{\theta}_{20}=-\mathrm{K}_{\mathrm{S}_{20}}\left(\theta_{20}-\theta_{\mathrm{g}}\right)-\mathrm{K}_{\mathrm{S}_{21}}\left(\theta_{20}-\theta_{21}\right)-\mathrm{C}_{\mathrm{S}_{20}}\left(\dot{\theta}_{20}-\dot{\theta}_{\mathrm{g}}\right) \\
& -\mathrm{C}_{\mathrm{S}_{21}}\left(\dot{\theta}_{20}-\dot{\theta}_{21}\right)-\left(\mathrm{C}_{\mathrm{B}_{9}}+\mathrm{C}_{\mathrm{B}_{10}}\right) \dot{\theta}_{20}-\mathrm{C}_{\mathrm{e}} \dot{\theta}_{20}-\mathrm{K}_{\mathrm{e}} \theta_{20} \\
& \mathrm{~J}_{\mathrm{m}_{21}} \ddot{\theta}_{21}=-\mathrm{K}_{\mathrm{S}_{21}}\left(\theta_{21}-\theta_{20}\right)-\mathrm{C}_{\mathrm{S}_{21}}\left(\dot{\theta}_{21}-\dot{\theta}_{20}\right)
\end{aligned}
$$


Where $T_{d}$ is the dynamic torque induced in gears, $n_{b}$ is the number of blades in each stage, $\mathrm{K}_{\mathrm{b}_{\mathrm{i}}}$ is the torsional stiffness of any turbine or compressor blade, and SR is the gear ratio.

The comprehensive model of the system including the electrical network interconnection to the system which is linked by an equivalent electrical stiffness is presented schematically in figure (3).

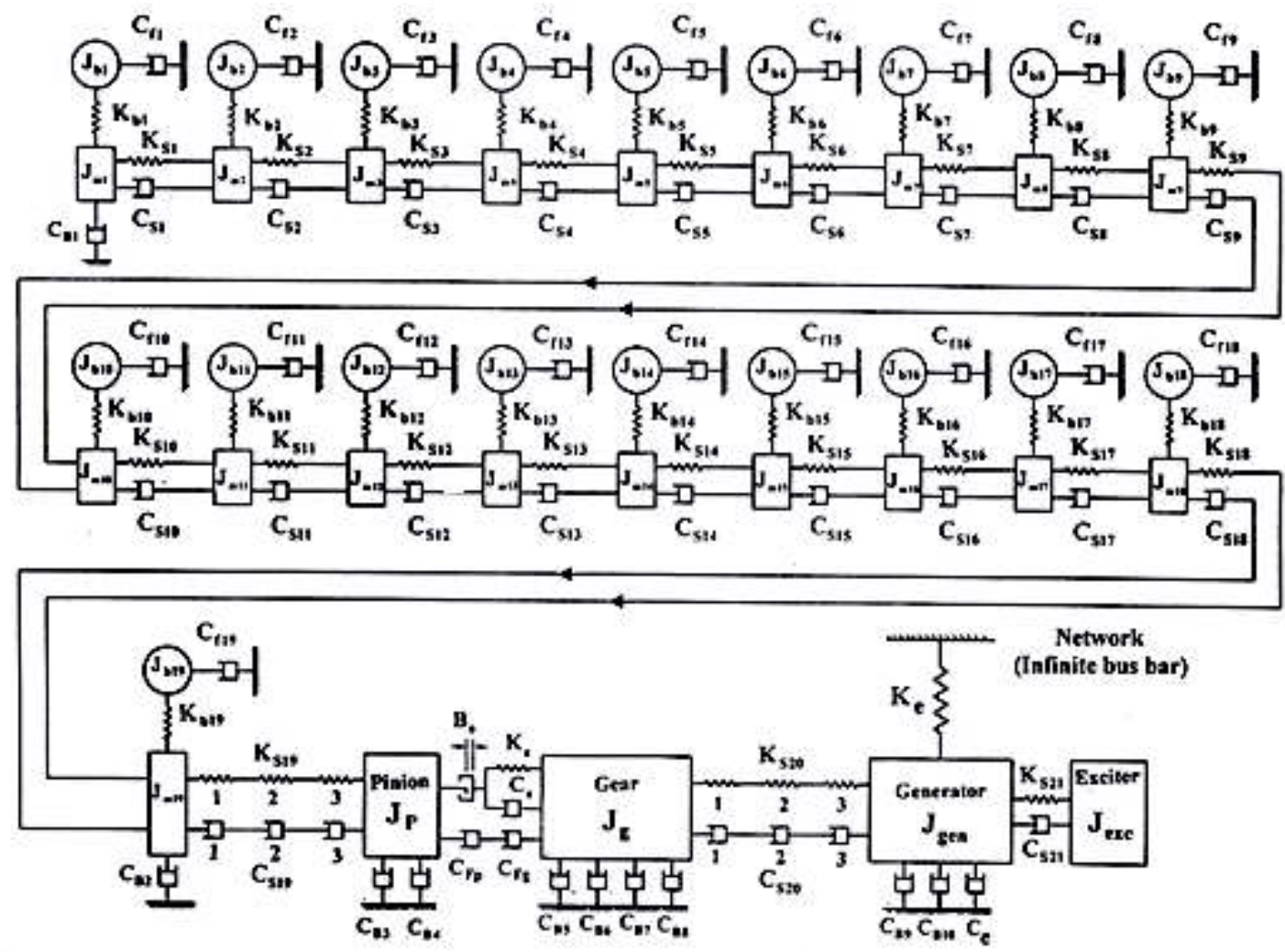

Figure (3): Mass-damping-spring model of the turbo-generator unit

Effect of Backlash

Backlash is commonly found in gears and similar mechanical linkages where the coupling is not perfect or continuously provided. In a majority of situation, backlash induces additional dynamic forces.

The dynamic equations of a gear system, during meshing, depends on four situations, as illustrated in figure (4) :

(i) If $\theta_{\mathrm{P}}-\theta_{\mathrm{g}}>\mathrm{B}_{\theta}$ then $\mathrm{T}_{\mathrm{d}}=\mathrm{K}_{\mathrm{g}}\left(\theta_{\mathrm{P}}-\theta_{\mathrm{g}}\right)+\mathrm{C}_{\mathrm{g}}\left(\dot{\theta}_{\mathrm{P}}-\dot{\theta}_{\mathrm{g}}\right)$

(ii) If $\mathrm{B}_{\theta}>\theta_{\mathrm{P}}-\theta_{\mathrm{g}}>-\mathrm{B}_{\theta}$ then $\mathrm{T}_{\mathrm{d}}=0.0$ (loss of contact)

This occurs between points 2 and 3 .

(iii) If $\theta_{\mathrm{g}}-\theta_{\mathrm{P}}>\mathrm{B}_{\theta}$ then $\mathrm{T}_{\mathrm{d}}=\mathrm{K}_{\mathrm{g}}\left(\theta_{\mathrm{g}}-\theta_{\mathrm{P}}\right)+\mathrm{C}_{\mathrm{g}}\left(\dot{\theta}_{\mathrm{g}}-\dot{\theta}_{\mathrm{P}}\right)$

(iv) If $\theta_{\mathrm{P}}-\theta_{\mathrm{g}}=\mathrm{B}_{\theta}$ or $\theta_{\mathrm{P}}-\theta_{\mathrm{g}}=-\mathrm{B}_{\theta}$ then $\mathrm{T}_{\mathrm{d}}=0.0$ (loss of contact)

Where $\mathrm{B}_{\theta}$ is the backlash. 
These four situations are considered and introduced in the dynamic equations of pinion and gear in the present multi massspring-damper model, hence in the simulation block diagram of the system.

Figure (4): Gear teeth backlash model

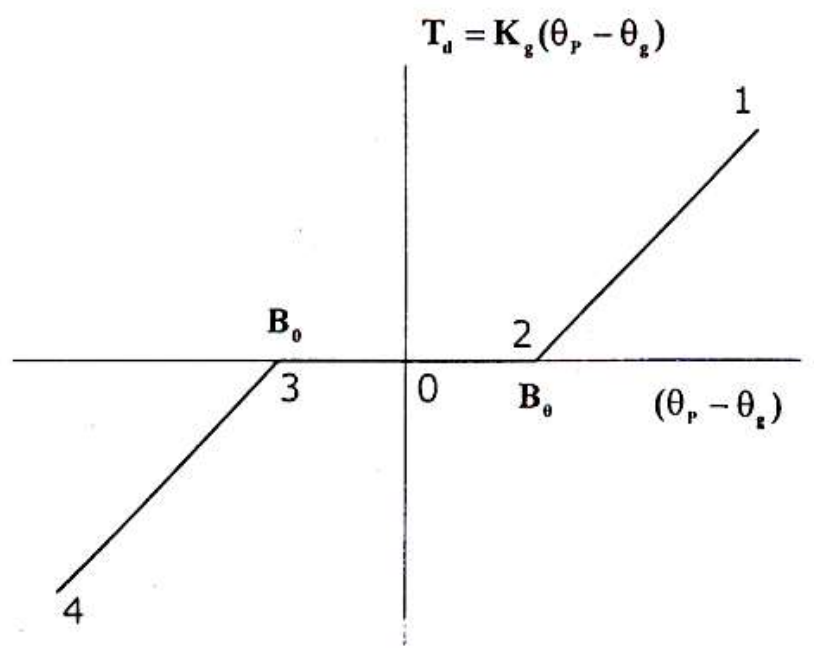

In developing equations (2) to (43), several assumptions are employed:

(1) Mistuning (variations in the dynamic properties of the blades) is ignored.

(2) Each blade of compressor and turbine is considered as one mass, flexibly attached to the shaft segment.

(3) Blades motion is independent of each other in each stage (i.e., no coupling between blades along the shaft exists).

(4) The shaft of the unit does not actually constitute a perfectly rigid connection between different components. As a good approximation, the rotor of the single component is divided into a number of segments. Each segment considered as a rigid lumped mass, torsionally connected through elastic elements of negligible masses. Each stage of turbine and compressor is connected to $\mathrm{n}_{\mathrm{b}}$ blades through elastic elements also. The whole system (mechanical part including compressor and turbine blades, gear system) and the (electrical part including generator and exciter) produces 23 masses connected by 22 springs. In turn, each of compressor and turbine stages connected to $n_{b}$ blades by $\mathrm{n}_{\mathrm{sp}}$ springs for each stage.

(5) Low contact gear ratio is used in the analysis. Specifically, the contact ratio is taken between one and two.

Estimation of Stiffness and Damping Coefficients

The following analysis is used to determine the linear or linearized estimation of the stiffness and damping coefficients appeared in the primarily derived equations (2) to (43).

Stiffness Coefficients

\section{Shaft Segment Stiffness Coefficients $\left(K_{S}\right)$}

Generally, for a stepped shaft segment having any number of steps, the equivalent stiffness (where the diameter and length of each step is not the same) is represented equivalently by:

$\frac{1}{\left(\mathrm{~K}_{\mathrm{S}}\right)_{\mathrm{eq}}}=\frac{1}{\mathrm{~K}_{\mathrm{S}_{1}}}+\frac{1}{\mathrm{~K}_{\mathrm{S}_{2}}}+\frac{1}{\mathrm{~K}_{\mathrm{S}_{3}}}+\cdots+\frac{1}{\mathrm{~K}_{\mathrm{S}_{\mathrm{s}_{\mathrm{st}}}}}$ 
The shaft segment stiffness can be given by the following standard expression:

$$
\mathrm{K}_{\mathrm{S}}=\frac{\mathrm{J}_{\mathrm{D}} \cdot \mathrm{G}}{\mathrm{L}} \quad(\mathrm{N} \cdot \mathrm{m} / \mathrm{rad})
$$

Then,

$$
\frac{1}{\left(\mathrm{~K}_{\mathrm{S}}\right)_{\mathrm{eq}}}=\frac{1}{\mathrm{~J}_{\mathrm{D}_{1}} \cdot \mathrm{G} / \mathrm{L}_{1}}+\frac{1}{\mathrm{~J}_{\mathrm{D}_{1}} \cdot \mathrm{G} / \mathrm{L}_{1}}+\frac{1}{\mathrm{JD}_{3} \cdot \mathrm{G} / \mathrm{L}_{3}}+\cdots+\frac{1}{\mathrm{JD}_{\mathrm{n}_{\mathrm{st}}} \cdot \mathrm{G} / \mathrm{L}_{\mathrm{n}_{\mathrm{st}}}}
$$

Or

$$
\left(\mathrm{K}_{\mathrm{S}}\right)_{\text {eq }}=\frac{1}{\frac{32}{\pi \mathrm{G}}\left[\frac{\mathrm{L}_{1}}{\mathrm{D}_{1}^{4}}+\frac{\mathrm{L}_{2}}{\mathrm{D}_{2}^{4}}+\frac{\mathrm{L}_{3}}{\mathrm{D}_{3}^{4}}+\cdots+\frac{\mathrm{L}_{\mathrm{st}}}{\mathrm{D}_{\mathrm{n}_{\mathrm{St}}}^{4}}\right]}
$$

Where $\mathrm{n}_{\mathrm{st}}$ is the number of steps in shaft segment, $\mathrm{L}$ is the segment length, $\mathrm{J}$ is the polar moment of inertia of segment section, $G$ is the torsional rigidity of segment material, and $D$ is the segment diameter.

\section{Gear or Mesh Stiffness (Kg)}

Reducing the speed of the turbine in the unit to that of the generator requires a gear system. Motion and torque transmission is achieved by permanent teeth contact. However, this arrangement is to some extent, elastic.

Yang and sun [7] derived an approximate, linear expression for the elastic force between single pair of steel gears teeth along common tangent to base circles as:

$$
\mathrm{F}=\frac{\pi \mathrm{EL} \delta}{4\left(1-v^{2}\right)}=\mathrm{K}_{\mathrm{g}} \cdot \delta
$$

Where $\delta$ is the magnitude of the interpenetration between two meshing teeth, or relative displacement between two teeth, L is the thickness of the teeth (face width), E is the Young's modulus of the gear material, $v$ is the Poisson's ratio of the gear material, $\mathrm{K}_{\mathrm{g}}$ is the linear mesh stiffness of the contact $(\mathrm{N} / \mathrm{m})$.

This expression has been derived according to hertzian law for elastic materials.

An approximated, linear expression for the elastic torque between the same pair of gears teeth has been obtained as compression between two isotropic elastic bodies.

$\mathrm{T}=\frac{\pi \mathrm{ELR}_{\mathrm{b}_{\mathrm{avg}} \mathrm{\theta}}^{\theta}}{4\left(1-v^{2}\right)}=\dot{\mathrm{K}}_{\mathrm{g} \cdot} \theta$

Where $R_{b_{a v g}}$ is the average radius of base circles of two gears, $\theta$ is the relative gear displacement between two teeth, and $K_{g}$ is the angular mesh stiffness (N.m/rad).

\section{Variable Mesh Stiffness}

Although, the stiffness during the contact of a single pair of teeth is considered as a constant, equation (53). It cannot be guaranteed that this will still be held for the entire gear motion. [7]. The stiffness of contact will change with the number of meshing teeth gear pairs during motion. This number alternates between one and two. Figure (5) shows a pair of spur 
gears with involute profile in mesh. Assuming that, this pair of teeth comes with contact starting at point $\mathrm{B}_{2}$ and separates at point $B_{1}$, where $B_{2}$ and $B_{1}$ are both on the common normal line. Three periods exist in terms of the number of the contact teeth pairs (contact ratio):

Figure (5): Geometrical relationships of teeth contact [7]

(A) From $B_{2}$ to $A_{2}$ In this region the preceding pair of teeth are still in contact, so we have two pairs of teeth in contact. Since the area of contact is doubled, it is reasonably, believed that the stiffness of hertzian contact ratio doubled. In this case, the stiffness is considered to be twice of that given by equation (53). i.e.

$\dot{K}_{\mathrm{g}}^{\prime}=\frac{\pi \mathrm{ELR}_{\mathrm{b}_{\mathrm{avg}}^{2}}^{2\left(1-v^{2}\right)}}{2\left({ }^{2}\right.}$

(B) From $A_{2}$ to $A_{1}$

In this region, the preceding pair of teeth has already separated, yet the succeeding pair has not come in contact. Therefore, we have a single pair of teeth in touch. In this case, the stiffness $\left(\mathrm{K}_{\mathrm{g}}\right)$ given in equation (53) holds.

(C) From $\mathrm{A}_{1}$ to $\mathrm{B}_{2}$

This region is the same as that in situation A, except that this pair of teeth becomes the new preceding pair, and another new pair of teeth starts contact in the region of $\mathrm{B}_{2} \mathrm{~A}_{2}$.

In fact, three regions of contact exist. Figure (6) illustrates the fluctuating characteristics of these three regions of meshing.

Here, for simplicity, the average value of this stiffness is used. It is taken as the sum of the discrete tooth stiffness values over mesh cycle divided by the number of mesh positions in the cycle $[8,9]$, i.e.,

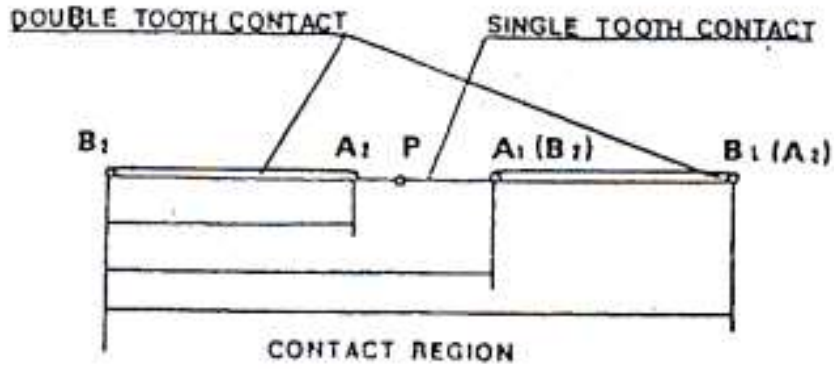

Figure (6): Alternation of the number of contact pairs [7]

$\left(\dot{K}_{\mathrm{g}}\right)_{\text {avg }}=\frac{1}{3}\left[\left(\dot{K}_{\mathrm{g}}\right)_{1}+\left(\dot{K}_{\mathrm{g}}\right)_{2}+\left(\dot{K}_{\mathrm{g}}\right)_{3}\right]=\frac{5 \pi \mathrm{E} \mathrm{L} \mathrm{R}_{\mathrm{b}_{\text {avg }}}^{2}}{12\left(1-v^{2}\right)}$ 


\section{Electrical Stiffness $\left(K_{e}\right)$}

When the energy conversion from mechanical to electrical form or the reverse takes place at a constant speed of the rotor in any synchronous machine (generator or motor) [10], The electrical torque:

$\left(\mathrm{T}_{\mathrm{el}}\right)=-$ the mechanical torque $\left(\mathrm{T}_{\mathrm{me}}\right)$

The negative sign indicates that when $\mathrm{T}_{\mathrm{el}}$ is positive, $\mathrm{T}_{\mathrm{me}}$ is negative (motor mode) and when $\mathrm{T}_{\mathrm{el}}$ is negative, $\mathrm{T}_{\mathrm{me}}$ is positive (generator mode)

When the speed rises, the instantaneous electrical torque $\mathrm{T}_{\mathrm{el}}$ and the instantaneous mechanical torque $\mathrm{T}_{\mathrm{me}}$ are related as:

$$
\mathrm{J}_{\text {gen }} \frac{\mathrm{d} \omega_{\mathrm{r}}}{\mathrm{dt}}=\mathrm{T}_{\mathrm{me}}-\mathrm{T}_{\mathrm{el}}=\mathrm{T}_{\mathrm{a}^{\prime}} \quad \text { (Generator mode) }
$$

Where $J_{\text {gen }}$ is the is mass moment of inertia of the generator rotor, $\omega_{r}$ is the angular speed of the generator rotor, $\mathrm{T}_{\mathrm{a}^{\prime}}$ is the accelerating torque.

Cleary, when the generator is accelerating, the mechanica 1 torque $\mathrm{T}_{\mathrm{me}}$ should be larger than the electrical torque $\mathrm{T}_{\mathrm{el}}$. On the other hand, the power developed by the generator per phase is given by, [10]:

$$
\mathrm{P}_{\mathrm{dev}}=\frac{\mathrm{v}_{\mathrm{fi}} \mathrm{V}_{\mathrm{t}}}{\mathrm{X}_{\mathrm{Sy}}} \sin \phi=\mathrm{T}_{\mathrm{el}} \cdot \omega_{\mathrm{r}}
$$

Where $V_{f i}$ is the induced or internal voltage per phase, $V_{t}$ is the terminal voltage per phase, $\mathrm{X}_{\mathrm{Sy}}$ is the synchronous reactance per phase, and $\phi$ is the power angle between $V_{o}$ and $V_{t}$. Hence,

$$
\mathrm{T}_{\mathrm{el}}=\frac{\mathrm{v}_{\mathrm{fi}} \cdot \mathrm{V}_{\mathrm{t}} \cdot \sin \phi}{\mathrm{x}_{\mathrm{Sy}} \cdot \omega_{\mathrm{r}}}
$$

This expression represents the electrical torque in its non-linear form.

The following approximate analysis has been done by Nasar and Unnewehr [10], to evaluate the electrical stiffness $\left(\mathrm{K}_{\mathrm{e}}\right)$, and it will be adopted in this work.

For two-pole, cylindrical-rotor, and assuming that the frequency of mechanical oscillations is small, so that the steady-state power angle characteristics can be used, the equation of rotational motion of this synchronous generator is:

$\mathrm{J}_{\text {gen }} \ddot{\theta}_{\mathrm{r}}=\mathrm{T}_{\mathrm{me}}-\mathrm{T}_{\mathrm{el}}$

Where $\theta_{\mathrm{r}}$ represents the angular displacement of the generator rotor.

Let the changes in $\theta_{\mathrm{r}}, \mathrm{T}_{\mathrm{el}}$ and $\mathrm{T}_{\mathrm{me}}$ caused by sudden load changes be represented by $\Delta \theta_{\mathrm{r}}, \Delta \mathrm{T}_{\mathrm{el}}$ and $\Delta \mathrm{T}_{\mathrm{me}}$ respectively, so that equation (58) modifies to the following:

$$
\left(\mathrm{T}_{\text {gen }} \frac{\mathrm{d}^{2}}{\mathrm{dt}^{2}}\right) \Delta \theta_{\mathrm{r}}=\Delta \mathrm{T}_{\mathrm{me}}-\Delta \mathrm{T}_{\mathrm{el}}
$$

The change in the electrical torque, from equation (57), is the following,

$$
\Delta \mathrm{T}_{\mathrm{el}}=\frac{\mathrm{V}_{\mathrm{fi}} \mathrm{V}_{\mathrm{t}}}{\mathrm{x}_{\mathrm{sy}} \omega_{\mathrm{r}}} \sin [\Delta \phi]
$$


Where $\mathrm{T}_{\mathrm{el}}$ is the electrical, electromagnetic or air gap torque, and $\omega_{\mathrm{r}}$ is the rotational speed of the generator rotor $=$ synchronous speed or electrical frequency under steady state conditions, $\omega_{\mathrm{r}}=\pi \mathrm{N}_{\mathrm{r}} / 30(\mathrm{rad} / \mathrm{sec})$.

It may be noticed that for constant voltages, only angle $(\phi)$ changes when load changes.

For small variations $\sin [\Delta \phi] \cong \Delta \phi$, therefore, equation (60) becomes:

$\Delta \mathrm{T}_{\mathrm{el}}=\mathrm{K}_{\mathrm{e}} \Delta \phi$

Where

$$
\mathrm{K}_{\mathrm{e}}=\frac{\mathrm{V}_{\mathrm{fi}} \mathrm{V}_{\mathrm{t}}}{\mathrm{X}_{\mathrm{sy}} \omega_{\mathrm{r}}}
$$

Which represent the electrical stiffness per phase. For 3-phase operation, the electrical stiffness is given by:

$\mathrm{K}_{\mathrm{e}}=3 \frac{\mathrm{V}_{\mathrm{fi}} \mathrm{V}_{\mathrm{t}}}{\mathrm{X}_{\mathrm{sy}} \omega_{\mathrm{r}}} \quad\left(\mathrm{N} \cdot \frac{\mathrm{m}}{\mathrm{rad}}\right)$

\section{Estimation of Damping Coefficients}

\section{Material Damping $\left(\mathrm{C}_{\mathrm{s}}\right)$}

Materials damping capacity is defined as "internal hysteresis" which is the property of a material which produces internal dissipation of energy under cyclic deformation [11].

The internal damping capacity of materials can be obtained from the stress-strain diagram shown in figure (6).

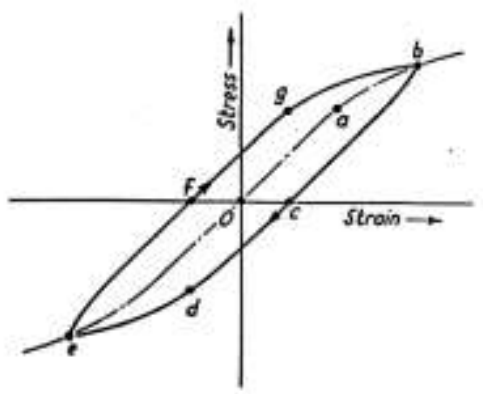

The complete diagram form a closed loop the area

Figure (6): Hysteresis loop [11] of which represents the energy dissipated in overcoming the internal friction of the material. This energy appears largely in the form of heat.

Damping in the elastic shaft elements between rigid lumped masses is due to the shaft material. Defining the critical damping $\left(\mathrm{C}_{\mathrm{c}}\right)$ and damping ratio $\left(\zeta_{\mathrm{s}}\right)$ as:

$\mathrm{C}_{\mathrm{c}}=2 \mathrm{~J}_{\mathrm{m}} \omega_{\mathrm{n}}$

And $\zeta_{\mathrm{s}}=\frac{\mathrm{C}_{\mathrm{s}}}{\mathrm{C}_{\mathrm{c}}}$

Where $\mathrm{C}_{\mathrm{s}}$ is the material damping coefficient.

Therefore, $\quad C_{s}=2 \zeta_{s} J_{m} \omega_{n}=2 \zeta_{s} J_{m} \sqrt{\frac{K_{s}}{J_{m}}}$

This yields,

$\mathrm{C}_{\mathrm{s}}=2 \zeta_{\mathrm{s}} \sqrt{\mathrm{K}_{\mathrm{S}} \mathrm{J}_{\mathrm{m}}}$ 
Shaft material damping can be estimated by considering that the damping exist between any two adjacent segments in a manner similar to that connecting two inertias as shown in figure (7). The damping coefficient can be approximated by

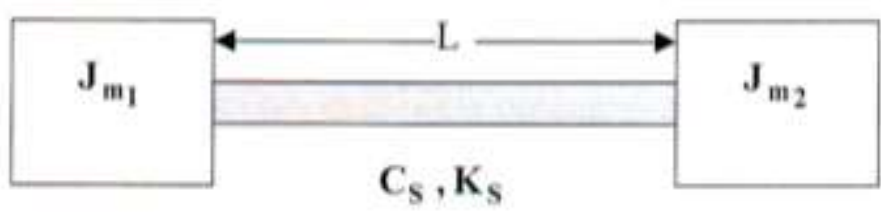

Figure (7): Two inertias with stiffness and damping [12]:

$$
\mathrm{C}_{\mathrm{S}}=2 \zeta_{\mathrm{s}} \sqrt{\mathrm{K}_{\mathrm{S}}\left(\mathrm{J}_{\mathrm{m}}\right)_{\mathrm{Sf}}}
$$

Where $\left(J_{m_{\text {eff }}}\right)_{S}$ is effective inertia of the two adjacent masses at two ends of the shaft segment that can be calculated as:

$$
\mathrm{J}_{\mathrm{m}}=\frac{\mathrm{J}_{\mathrm{m}_{1}} \mathrm{~J}_{\mathrm{m}_{2}}}{\mathrm{~J}_{\mathrm{m}_{1}}+\mathrm{J}_{\mathrm{m}_{2}}}
$$

Substitute equation (68) into equation (67) to get the general expression of the material damping coefficient:

$$
\mathrm{C}_{\mathrm{S}}=2 \zeta_{\mathrm{s}} \sqrt{\frac{\mathrm{J}_{\mathrm{m}_{1}} \mathrm{~J}_{2}}{\mathrm{~J}_{\mathrm{m}_{1}}+\mathrm{J}_{\mathrm{m}_{2}}}}
$$

Where $\zeta_{s}$ is the damping ratio of shaft material.

Experiments have shown that $\zeta_{\mathrm{s}}$ ranges between 0.005 to 0.075 for steels [7].

\section{Mesh Damping or Gear Damping $\left(\mathrm{C}_{\mathrm{g}}\right)$}

When two elastic bodies impact each other, most of the elastic strain energy is restored, but a fraction of which will be dissipated in the form of heat due to random molecular vibration. This energy loss can be considered as a damping effect during impact [13]. Generally, the damping coefficient is represented by (equation 67):

$\mathrm{C}_{\mathrm{S}}=2 \zeta \sqrt{\mathrm{KJ}}$

Then, the damping coefficient of any two meshing gears due to impact between their teeth can be represented by:

$\mathrm{C}_{\mathrm{g}}=2 \zeta_{\mathrm{g}} \sqrt{\left(\mathrm{Kg}^{\prime}\right)_{\mathrm{avg}}\left(\mathrm{J}_{\mathrm{m}}{ }_{\mathrm{eff}}\right)_{\mathrm{g}}}$

Where $\zeta_{\mathrm{g}}$ is the is the damping ratio of gear material, $\left(\mathrm{Kg}^{\prime}\right)_{\text {avg }}$ is the gear or mesh stiffness, $\left(\mathrm{J}_{\mathrm{m}_{\mathrm{eff}}}\right)_{\mathrm{g}}$ is the effective inertia of two meshing gears with speed ratio (SR).

$\left.\left(\mathrm{J}_{\mathrm{m}}\right)_{\text {eff }}\right)_{\text {gears }}$ can be expressed by the following expression:

$$
\left(\mathrm{J}_{\mathrm{m}}\right)_{\text {gears }}=\frac{\mathrm{J}_{\mathrm{mp}}+\mathrm{J}_{\mathrm{mg}}}{(\mathrm{SR})^{2} \cdot \mathrm{J}_{\mathrm{mp}}+\mathrm{J}_{\mathrm{mg}}}
$$

Therefore,

$$
\mathrm{C}_{\mathrm{g}}=2 \zeta_{\mathrm{g}}\left(\mathrm{Kg}^{\prime}\right)_{\mathrm{avg}} \frac{\mathrm{J}_{\mathrm{mp}}+\mathrm{J}_{\mathrm{mg}}}{(\mathrm{SR})^{2} \cdot \mathrm{J}_{\mathrm{mp}}+\mathrm{J}_{\mathrm{mg}}}
$$

Where $\mathrm{J}_{\mathrm{mp}}$ and $\mathrm{J}_{\mathrm{mg}}$ is the polar moment of inertia of pinion and gear respectively 
Measurements have shown that, $\zeta_{\mathrm{g}}$ ranges between 0.03 to $0.17[14,15]$.

\section{Sliding Friction Damping in Pinion and Gear $\left(\mathrm{C}_{\mathrm{F}_{\mathbf{p}}}, \mathrm{C}_{\mathrm{F}_{\mathbf{g}}}\right)$}

This type of relative damping occurs due to frictional forces of the driving and driven gears. Figure (8) shows the engagement of pinion and gear teeth. The normal force $F_{\text {nor }}$ is acted along the common tangent to base circles and the friction force $F_{F}$ is acted along the common tangent to teeth which is perpendicular to base circles common tangent. Using the following relationship:

$\mathrm{F}_{\mathrm{F}}=\mu \mathrm{F}_{\text {nor }}$

The friction torques along the common tangent to pitch circles are,

$\left(\mathrm{T}_{\mathrm{F}}\right)_{\text {pinion }}=\mathrm{F}_{\mathrm{F}} \sin \psi \mathrm{R}_{\mathrm{p}}=\mu \mathrm{F}_{\text {nor }} \sin \psi \mathrm{R}_{\mathrm{p}}$

$\left(\mathrm{T}_{\mathrm{F}}\right)_{\text {gear }}=\mathrm{F}_{\mathrm{F}} \sin \psi \mathrm{R}_{\mathrm{g}}=\mu \mathrm{F}_{\text {nor }} \sin \psi \mathrm{R}_{\mathrm{g}}$

Where $\psi$ is the pressure angle, $R_{p}$ and $R_{g}$ are the pitch radii of pinion and gear respectively

The frictional force losses during the engagement of two gears arise from two types of relative motion, namely, sliding and rolling of involute teeth with respect to each other. In all other positions, however, the meshing action is a combination of rolling and sliding. Since rolling is considerably smaller than the sliding resistance, its contribution to the total friction is usually ignored [15, 16, and 17].

Sliding friction in gear mesh has an effect on the system dynamics as a source of energy dissipation [18], in other words, it can influence the system with its damping characteristics [19].

Buckingham [20] has developed a semi-empirical formula for the average friction coefficient $\mu_{\text {avg }}$ ) as:

$$
\mu_{\mathrm{avg}}=0.05 \mathrm{e}^{-0.125 \mathrm{vS}}+0.002 \sqrt{(\mathrm{VS})_{\mathrm{avg}}}
$$


Where (VS) $)_{\text {avg }}$ is the average sliding velocity in ( $\left.\mathrm{ft} / \mathrm{min}\right)$, alternatively, Buckingham formula stated earlier can be rewritten using SI units, when the average sliding velocity (VS) in $(\mathrm{m} / \mathrm{s})$ as:

$\mu_{\mathrm{avg}}=0.028 \sqrt{(\mathrm{VS})_{\mathrm{avg}}}$

The losses in gearing due to relative rolling motion, by using this approach, were completely disregarded. Examples on this approach have been presented in the literature $[21,22]$.

Now, the average sliding velocity is given by the following expression:

$(\mathrm{VS})_{\mathrm{avg}}=\frac{\left(\mathrm{VS}_{\mathrm{apr}}+\mathrm{VS}_{\mathrm{rec}}\right)}{2}$

Where $\mathrm{VS}_{\mathrm{apr}}$ is the approach sliding velocity, and it is given by:

$\mathrm{VS}_{\mathrm{apr}}=\left(\omega_{\mathrm{p}}+\omega_{\mathrm{g}}\right) \cdot \mathrm{AP}$

Also $\mathrm{VS}_{\text {rec }}$ is the recess sliding velocity:

$$
\mathrm{VS}_{\mathrm{rec}}=\left(\omega_{\mathrm{p}}+\omega_{\mathrm{g}}\right) \cdot \mathrm{PB}
$$

After substituting equation (79) and (80) into equation (78), the average sliding velocity can be obtained in terms of path of contact $(\mathrm{AB})$ and the average angular velocity $\left(\omega_{\mathrm{avg}}\right)$ as:

$(\mathrm{VS})_{\mathrm{avg}}=\mathrm{AB} \cdot\left(\omega_{\mathrm{avg}}\right)$

Where

$\mathrm{AB}=\mathrm{AP}+\mathrm{PB}$

And

$\omega_{\mathrm{avg}}=\frac{\omega_{\mathrm{p}}+\omega_{\mathrm{g}}}{2}$

Where $\omega_{p}, \omega_{g}$ are the angular velocities of pinion and gear respectively, AP is the path of approach, and PB is the path of recess.

Substituting equation (81) into equation (77) to get:

$$
\mu_{\mathrm{avg}}=0.028 \sqrt{\mathrm{AB}} \omega_{\mathrm{avg}}^{\frac{1}{2}}
$$

The frictional torques $\left(\mathrm{T}_{\mathrm{F}_{\mathrm{p}}}\right.$ and $\mathrm{T}_{\mathrm{Fg}}$ ) are obtained by substituting equation (81) into equations (74 and 75) as follows:

$$
\begin{aligned}
\mathrm{T}_{\mathrm{F}} & =\left[0.028 \sqrt{\mathrm{AB}} \omega_{\text {avg }}^{\frac{1}{2}}\right] \mathrm{F}_{\text {nor }} \mathrm{R}_{\mathrm{p}} \sin \Psi \\
\mathrm{T}_{\mathrm{Fg}} & =\left[0.028 \sqrt{\mathrm{AB}} \omega_{\text {avg }}^{\frac{1}{2}}\right] \mathrm{F}_{\text {nor }} \mathrm{R}_{\mathrm{g}} \sin \Psi
\end{aligned}
$$

Since $\mathrm{F}_{\text {nor }}, \sin \Psi, \mathrm{R}_{\mathrm{p}}$, and $\mathrm{R}_{\mathrm{g}}$ are constants, the friction torques $\mathrm{T}_{\mathrm{F}_{\mathrm{p}}}$ and $\mathrm{T}_{\mathrm{F}_{\mathrm{g}}}$ become only functions of the average angular velocities $\left(\omega_{p}\right.$ and $\left.\omega_{g}\right)$. 
Let

$\mathrm{K}_{1}=\mathrm{F}_{\mathrm{nor}} \mathrm{R}_{\mathrm{p}} \sin \psi$

$\mathrm{K}_{2}=\mathrm{F}_{\text {nor }} \mathrm{R}_{\mathrm{g}} \sin \Psi$

Then equations ( 85 and 86 ) can be written as:

$\mathrm{T}_{\mathrm{Fp}}=\mathrm{K}_{1}\left[0.028 \sqrt{\mathrm{AB}} \omega_{\mathrm{avg}}^{\frac{1}{2}}\right]$

$\mathrm{T}_{\mathrm{Fg}}=\mathrm{K}_{2}\left[0.028 \sqrt{\mathrm{AB}} \omega_{\mathrm{avg}}^{\frac{1}{2}}\right]$

These expressions are non-linear form of $\mathrm{T}_{\mathrm{Fp}}$ and $\mathrm{T}_{\mathrm{Fg}_{\mathrm{g}}}$. The linearization of these expressions gives the damping coefficients of frictional moments in pinion and gear $\left(\mathrm{C}_{\mathrm{F}_{\mathrm{p}}}\right.$ and $\mathrm{C}_{\mathrm{F}_{\mathrm{g}}}$ ) as following:

$$
\Delta \mathrm{T}_{\mathrm{F}_{\mathrm{p}}}=\left|\frac{\partial \mathrm{T}_{\mathrm{F}_{\mathrm{p}}}}{\partial \omega_{\mathrm{avg}}}\right|_{\mathrm{i}} \Delta \omega_{\mathrm{avg}}=\mathrm{C}_{\mathrm{F}_{\mathrm{p}}} \Delta \omega_{\mathrm{avg}}
$$

Also

$\Delta \mathrm{T}_{\mathrm{Fg}_{\mathrm{g}}}=\left|\frac{\partial \mathrm{T}_{\mathrm{Fg}}}{\partial \omega_{\mathrm{avg}}}\right|_{\mathrm{i}} \Delta \omega_{\mathrm{avg}}=\mathrm{C}_{\mathrm{Fg}_{\mathrm{g}}} \Delta \omega_{\mathrm{avg}}$

Then,

$C_{F_{p}}=\left|\frac{\partial T_{F_{p}}}{\partial \omega_{\text {avg }}}\right|_{i}, \quad C_{F_{g}}=\left|\frac{\partial T_{F_{g}}}{\partial \omega_{\text {avg }}}\right|_{i}$

Where $\mathrm{C}_{\mathrm{F}_{\mathrm{p}}}$ and $\mathrm{C}_{\mathrm{F}_{\mathrm{g}}}$ are constants represents the slopes of the curves of $\mathrm{T}_{\mathrm{F}_{\mathrm{p}}}$ versus $\omega_{\mathrm{avg}}$ and $\mathrm{T}_{\mathrm{F}_{\mathrm{g}}}$ versus $\omega_{\mathrm{avg}}$ at the reference positions.

Therefore,

$$
\begin{array}{cc}
\mathrm{C}_{\mathrm{F}_{\mathrm{p}}}=\mathrm{K}_{1}\left[\frac{0.014 \sqrt{\mathrm{AB}}}{\sqrt{\omega_{\mathrm{avg}}}}\right] & \text { N. } \frac{\mathrm{m}}{\mathrm{rad}} / \mathrm{sec} \\
\mathrm{C}_{\mathrm{F}_{\mathrm{g}}}=\mathrm{K}_{2}\left[\frac{0.014 \sqrt{\mathrm{AB}}}{\sqrt{\omega_{\mathrm{avg}}}}\right] & \text { N. } \frac{\mathrm{m}}{\mathrm{rad}} / \mathrm{sec}
\end{array}
$$

\section{Bearing Oil film Damping Coefficient $\left(C_{B}\right)$}

The turbo-generator unit has ten journal bearings. Journal bearings or fluid film bearings play a significant role in the vibrational behavior of the rotor, both laterally and torsionally. Generally, the frictional forces in journal bearing may be obtained from fluid shear stresses at journal and bearing surfaces, i.e., for $\mathrm{Z}=0$ and $\mathrm{Z}=\mathrm{h}$ respectively as shown in figure

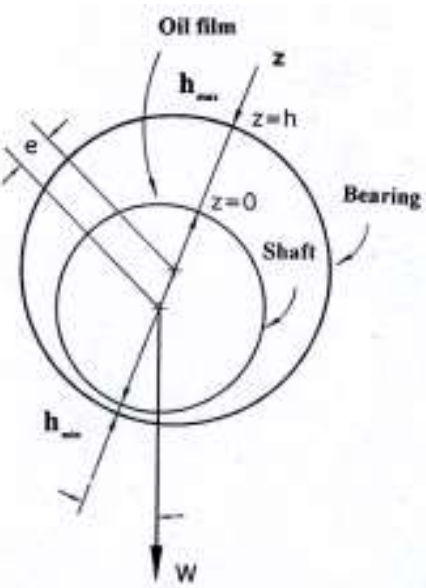
(9).

Figure (9): Journal bearing 
In steady running, the total drag or frictional force for both surfaces due to rotation is given by [23, 24]:

$$
\mathrm{F}_{\mathrm{B}}=\frac{\mathrm{CL} \in \mathrm{W}}{2 \mathrm{R}} \sin \varphi+\frac{2 \pi \xi U \mathrm{UL} \mathrm{L}_{\mathrm{B}}}{\left(1-\epsilon^{2}\right)^{1 / 2} \mathrm{CL}}
$$

The above relationship consists of two parts, the first part arises from the offset between the center of the shaft and that of the bearing. The second part is based on Newtonian friction.

Where $\mathrm{w}$ is the load on the bearing, $\epsilon$ is the bearing eccentricity ratio $(\epsilon=\mathrm{e} / \mathrm{CL})$, e is the eccentricity, $L_{B}$ is the bearing length, $C L$ is the radial clearance, $\varphi$ is the attitude angle of the bearing, $\mathrm{R}$ is the bearing radius, and $\xi$ is the absolute viscosity of the bearing oil, figure (9).

Frictional torque $=$ frictional force $*$ journal radius. This gives,

$$
\mathrm{T}_{\mathrm{B}}=\mathrm{F}_{\mathrm{B}} \cdot \mathrm{R}=\frac{\mathrm{CL} \epsilon \mathrm{W}}{2 \mathrm{R}} \sin \varphi+\frac{2 \pi \xi \mathrm{UR} \mathrm{L_{B }}}{\left(1-\epsilon^{2}\right)^{1 / 2} \mathrm{CL}}
$$

But the linear velocity is $U=\omega . R$.

Therefore, $\mathrm{T}_{\mathrm{B}}=\frac{\mathrm{CL} \epsilon \mathrm{W}}{2 \mathrm{R}} \sin \varphi+\frac{2 \pi \xi U \mathrm{R}^{3} \mathrm{~L}_{\mathrm{B}}}{\left(1-\epsilon^{2}\right)^{1 / 2} \mathrm{CL}}$

The first part of equation (97) is independent on the speed of rotation $(\omega)$. The frictional torque represents a source of dissipation of energy and hence provides a damping action. This equation is the non-linear form of that frictional or damping torque. The oil film coefficient is obtained by linearizing this equation as the following:

$\Delta \mathrm{T}_{\mathrm{B}}=\left|\frac{\partial \mathrm{T}_{\mathrm{B}}}{\partial \omega}\right|_{\mathrm{i}} \Delta \omega=\mathrm{C}_{\mathrm{B}} \Delta \omega$

Where, $C_{B}$ is a constant represents the slope of the curve of $T_{B}$ versus $\omega$ at the reference position.

Then $C_{B}=\frac{2 \pi \xi U R^{3} L_{B}}{\left(1-\epsilon^{2}\right)^{1 / 2} C L}$

\section{Electrical Damping $\left(\mathrm{C}_{\mathbf{e}}\right)$}

Alternating current generators (alternators) and motors have practically no-self damping capacity. The damping of an alternator is due to current induced in the pole faces of the rotor by the movement of the flux to and fro across the pole face during oscillation. In certain circumstances, this damping can become negative, in which case the system will become unstable resulting in a large growth of oscillatory amplitude if there is insufficient positive damping in the system as a whole. It is usual, therefore, to supplement the damping characteristic of the machine by special damper winding, embedded in the pole faces. The lower is the resistance of these windings the greater is their damping effect. These windings are similar to squirrel cage induction motor winding and sometimes called amortisseur [11].

As approximate expression for the specific damping, Wilson [11] has derived torque of an alternating current machine fitted with damper windings as follows:

In general, the driving torque is proportional to some power of the rotational velocity, i.e.,

$$
\mathrm{T}_{\mathrm{dr}}=\mathrm{K} \omega^{\mathrm{Z}}
$$


Where $\mathrm{T}_{\mathrm{dr}}$ is the driving torque $(\mathrm{N} . \mathrm{m}), \omega$ is the rotational velocity $(\mathrm{rad} / \mathrm{sec})$ and $(\mathrm{K}, \mathrm{Z})$ are constants.

For small variations of rotational speed, the damping torque per unit angular velocity (i.e. damping coefficient $\mathrm{C}_{\mathrm{e}}$ ) is the instantaneous slope of the torque-speed curve at the point of question (reference point),

$\mathrm{C}_{\mathrm{e}}=$ damping torque/unit velocity $=\frac{\mathrm{d}}{\mathrm{d} \omega}\left(\mathrm{T}_{\mathrm{dr}}\right)=\mathrm{Z} \mathrm{K \omega}{ }^{\mathrm{Z}-1}$

Substituting the constant, ( $\left.K=\frac{\mathrm{T}_{\mathrm{dr}}}{\omega^{\mathrm{Z}}}\right)$ from equation (100) and after some manipulation we have the damping coefficient as:

$C_{e}=Z \frac{T_{d r}}{\omega^{Z}} \omega^{Z-1}=Z \frac{T_{d r}}{\omega}=\frac{2 T_{d r}}{2 \pi N / 60}$

Or $\quad \mathrm{C}_{\mathrm{e}}=\frac{9.5 \mathrm{Z} \mathrm{T} \mathrm{dr}}{\mathrm{N}}$

It may be noticed that since the damping torque is proportional to velocity, the damping of viscous nature. The value of constant $\mathrm{Z}$ in equation (103), in practice, is generally greater than one, i.e., more than one percent increase of torque is required to produce one percent increase in speed. The actual value of $\mathrm{Z}$ depends on the torque/speed characteristics of the individual machine.

The electrical damping coefficient of an alternator or synchronous generator can be estimated from the general equation (103) as:

$\mathrm{C}_{\mathrm{e}}=\frac{9.55 \mathrm{ZT}_{\text {gen }}}{\mathrm{N}_{\text {gen }}}$

Where $\mathrm{T}_{\text {gen }}$ is the torque driving the generator and $\mathrm{N}_{\text {gen }}$ is the generator rpm.

For normal machines, it may be assumed that $13 \%$ to $14 \%$ increase of torque is required to produce $1 \%$ change of speed, i.e. $Z=13$ to 14 [11], Taking $Z=13.5$, therefore,

$$
\mathrm{C}_{\mathrm{e}}=\frac{129 \mathrm{~T}_{\text {gen }}}{\mathrm{N}_{\text {gen }}}
$$

\section{Fluid Damping or Velocity-Squared Damping $\left(C_{f}\right)$}

Velocity-squared damping (non-viscous damping) is commonly used to describe the damping mechanism of a system vibrating in a fluid medium. The damping force is assumed to be proportional to the square of the velocity and can be approximated by [6]:

$\mathrm{F}_{\mathrm{da}}=\left[\frac{\mathrm{C}_{\text {Drag }} \rho \mathrm{A}_{\mathrm{Pr}}}{2}\right] \dot{\mathrm{y}}^{2}$

Where $\dot{y}$ is the velocity of vibrating body relative to fluid medium $(\mathrm{m} / \mathrm{s}), \mathrm{C}_{\text {Drag }}$ is the drag coefficient (dimensionless), $A_{P r}$ is the projected area of body perpendicular to $\dot{y}\left(\mathrm{~m}^{2}\right)$, and $\rho$ is the mass density of fluid $\left(\mathrm{kg} / \mathrm{m}^{3}\right)$.

The relationship $y=r_{m n} \theta_{b}$ and its derivatives can be substituted into equation (104) to obtain the damping force in terms of the independent coordinate $\theta$ as: 


$$
\mathrm{F}_{\mathrm{da}}=\left[\frac{\mathrm{C}_{\text {Drag }} \rho \mathrm{A}_{\mathrm{Pr}}}{2}\right] \mathrm{r}_{\mathrm{mn}}^{2} \dot{\theta}_{\mathrm{b}}^{2}
$$

Where $r_{m n}$ is the mean radius of a single compressor or turbine blade, and $\theta_{b}$ is the angular displacement of blade center relative to shaft center.

The equivalent-viscous damping coefficient or fluid damping coefficient $\left(\mathrm{C}_{\mathrm{F}}\right)$ can be represented by the following relationship:

$$
\begin{aligned}
& \mathrm{C}=\mathrm{C}_{\mathrm{f}}=\frac{4}{3 \pi} \mathrm{C}_{\text {Drag }} \rho \mathrm{A}_{\mathrm{Pr}} \mathrm{r}_{\mathrm{mn}}{ }^{3}|\Theta| \omega_{\mathrm{n}} \\
& \text { Or } \\
& \mathrm{C}_{\mathrm{f}}=\frac{4}{3 \pi} \mathrm{C}_{\text {Drag }} \rho \mathrm{A}_{\mathrm{Pr}} \mathrm{r}_{\mathrm{mn}}{ }^{3}|\Theta| \sqrt{\frac{\mathrm{K}_{\mathrm{b}}}{\mathrm{J}_{\mathrm{b}}}}
\end{aligned}
$$

Where $|\Theta|$ is the peak angular amplitude of vibration of blade at resonance $(\mathrm{rad}), \mathrm{K}_{\mathrm{b}}$ is the blade stiffness $(\mathrm{N} . \mathrm{m} / \mathrm{rad})$, and $\mathrm{J}_{\mathrm{b}}$ is polar mass moment of inertia of the blade $\left(\mathrm{kg} \cdot \mathrm{m}^{2}\right)$.

Analysis of engine test results and rig investigations has shown that the mechanical damping (internal material damping) of the blade is small, and that the damping is mainly aerodynamic (fluid damping) under a constant excitation force. The angular peak amplitude at resonance $|\Theta|$ is approximately equal to thirty times the corresponding deflection due to static load by dead weight of blade [25].

\section{Results}

The present work deals with the simulation of the angular motion dynamics of the turbogenerator unit. Lumped mass system with the inertias of the main parts and the blades and the dynamic coefficients (stiffness and damping) has been fully predicted. In the present study, the axial flow compressor consists of seventeenth stages, which is the actual number of stages in the compressor of any of the twelve turbo-generator units under study of Mosul gas turbine power station. Also the turbine, which consists of two stages, the pinion, gear and generator are included so that the integral parts of the unit are simulated. To perform the calculations, a basic language computer program is developed and the actual data taken from the station catalogues as listed in table (1), are used in the program.

The data presented in table (2) are inserted into the computer program. These are obtained either from the available manufacturers data of the units or by direct measurement accomplished on each part in the absence of the foregoing information. 
Table (1): Summary of the data of the twenty-three lumped mass system of the turbo-generator unit

\begin{tabular}{|c|c|c|c|c|c|c|}
\hline No. & Lumped mass name & $\begin{array}{c}\text { Mass } \\
(\mathbf{k g})\end{array}$ & $\begin{array}{c}\text { Number of } \\
\text { blades }\end{array}$ & $\begin{array}{c}\text { Approximate } \\
\text { blade thickness } \\
(\mathbf{m m})\end{array}$ & $\begin{array}{l}\text { Approximate } \\
\text { blade width } \\
\text { ( } \mathbf{~ m m ~ ) ~}\end{array}$ & $\begin{array}{l}\text { Blade } \\
\text { height } \\
(\mathrm{mm})\end{array}$ \\
\hline 1 & Compressor stage 1 & 44 & 28 & 6 & 140 & 208 \\
\hline 2 & Compressor stage 2 & 23 & 32 & 4.5 & 110 & 185 \\
\hline 3 & Compressor stage 3 & 17.3 & 36 & 4 & 105 & 164 \\
\hline 4 & Compressor stage 4 & 15.4 & 40 & 4 & 100 & 144 \\
\hline 5 & Compressor stage 5 & 11.9 & 44 & 4 & 78 & 128 \\
\hline 6 & Compressor stage 6 & 12.6 & 49 & 4 & 70 & 115 \\
\hline 7 & Compressor stage 7 & 12.6 & 54 & 4 & 70 & 115 \\
\hline 8 & Compressor stage 8 & 12.6 & 59 & 4 & 70 & 115 \\
\hline 9 & Compressor stage 9 & 12.6 & 64 & 4 & 70 & 115 \\
\hline 10 & Compressor stage 10 & 12.6 & 69 & 4 & 70 & 115 \\
\hline 11 & Compressor stage 11 & 12.6 & 75 & 4 & 70 & 115 \\
\hline 12 & Compressor stage 12 & 12.6 & 81 & 4 & 70 & 115 \\
\hline 13 & Compressor stage 13 & 12.6 & 87 & 4 & 70 & 115 \\
\hline 14 & Compressor stage 14 & 12.6 & 94 & 4 & 70 & 115 \\
\hline 15 & Compressor stage 15 & 12.6 & 101 & 4 & 70 & 115 \\
\hline 16 & Compressor stage 16 & 12.6 & 108 & 4 & 70 & 115 \\
\hline 17 & Compressor stage 17 & 12.6 & 115 & 4 & 70 & 115 \\
\hline 18 & Turbine stage 1 & 82.2 & 90 & 18 & 60 & 95 \\
\hline 19 & Turbine stage 2 & 271.1 & 120 & 18 & 60 & 235 \\
\hline 20 & Pinion & 570 & & & & \\
\hline 21 & Gear & 1568 & & & & \\
\hline 22 & Generator & 10877 & & & & \\
\hline 23 & Exciter & 1221 & & & & \\
\hline
\end{tabular}

Table (2): Actual system specifications taken from station references

\begin{tabular}{|c|c|c|c|c|}
\hline No. & Item & Symbol & Values & Units \\
\hline 1 & Compressor shaft outer diameter & d & 700 & $\mathbf{m m}$ \\
\hline 2 & Rotational speed of gas turbine shaft & & 5100 & rpm \\
\hline 3 & Rotational speed of generator shaft & & 3000 & rpm \\
\hline 4 & Speed ratio & SR & 1.7 & \\
\hline 5 & Pinion pitch circle diameter & $d_{p}$ & 475 & $\mathbf{m m}$ \\
\hline 6 & Gear pitch circle diameter & $d_{g}$ & 808 & $\mathbf{m m}$ \\
\hline 7 & Gear face width & & 410 & $\mathbf{m m}$ \\
\hline 8 & Number of pinion teeth & & 58 & \\
\hline 9 & Number of gear teeth & & 99 & \\
\hline 10 & Module & $\mathbf{m}$ & 8 & $\mathbf{m m}$ \\
\hline 11 & Rotor generator diameter & $\mathbf{d}_{\text {gen }}$ & 764 & $\mathbf{m m}$ \\
\hline 12 & Rotor exciter diameter & $\mathbf{D}_{\text {exc }}$ & 600 & $\mathbf{m m}$ \\
\hline 13 & Rotor exciter length & $\mathbf{L}_{\mathrm{exc}}$ & 550 & $\mathbf{m m}$ \\
\hline 14 & Poissons's ratio & $\boldsymbol{v}$ & 0.3 & \\
\hline 15 & Absolute viscosity of bearing oil & $\xi$ & 0.0198171 & $\mathbf{N . s} / \mathbf{m}^{2}$ \\
\hline 16 & Rated power & & 20 & MW \\
\hline 17 & Terminal voltage & $V_{t}$ & $11000(\mathrm{~L}-\mathrm{L})$ & Volt \\
\hline 18 & Induced voltage / phase & $\mathbf{E}_{\mathrm{fi}}$ & 120 & Volt \\
\hline 19 & Stator resistance / phase & $\mathbf{R}$ & 0.0122 & Ohm \\
\hline 20 & Modulus of elasticity of $\mathrm{Ni}-\mathrm{Cr}$ steel & $\mathbf{E}$ & 208 & GPa \\
\hline 21 & Modulus of rigidity of Ni-Cr steel & G & 82 & GPa \\
\hline 22 & 1 per unit torque & 1 P.U. & 63622 & N.M \\
\hline
\end{tabular}


A summary of the calculation results are given in table (3) and (4). The calculations include effective polar mass moment of inertia of each lumped mass and blade, and the estimated values of dynamic coefficients (both stiffness and damping coefficients). In order to estimate the torsional natural frequencies and mode shapes, the system Eigen values and Eigen vectors are determined depending on the adopted model. The turbo-generator rotor system as specified has 42 degrees of freedom. By using the state-space technique for the solution of system equations, the 42 ordinary second order linear differential equations becomes 84 ordinary first order linear differential equations.

Table (3): Summary of the first set of results of the twenty-three shaft masses used in the Simulation

\begin{tabular}{|c|c|c|c|c|}
\hline No. & Lumped mass name & $\begin{array}{l}\text { Blade stiffness } \\
\text { (N.m/rad) }\end{array}$ & $\begin{array}{l}\text { Mass moment of } \\
\text { inertia of lumped } \\
\text { mass }\left(\mathrm{kg} \cdot \mathrm{m}^{2}\right)\end{array}$ & $\begin{array}{l}\text { Mass moment of } \\
\text { inertia of blade ( } \\
\text { kg.m²) }\end{array}$ \\
\hline 1 & Compressor stage 1 & 10758 & 41.12 & $1.978 * 10^{-2}$ \\
\hline 2 & Compressor stage 2 & 4508 & 30.41 & $8.2 * 10^{-3}$ \\
\hline 3 & Compressor stage 3 & 3846 & 28.29 & $4.85 * 10^{-3}$ \\
\hline 4 & Compressor stage 4 & 4751 & 26.7 & $3.126 * 10^{-3}$ \\
\hline 5 & Compressor stage 5 & 4690 & 20.64 & $1.713 * 10^{-3}$ \\
\hline 6 & Compressor stage 6 & 5214 & 18.45 & $1.115 * 10^{-3}$ \\
\hline 7 & Compressor stage 7 & 5214 & 18.67 & $1.115 * 10^{-3}$ \\
\hline 8 & Compressor stage 8 & 5214 & 18.92 & $1.115 * 10^{-3}$ \\
\hline 9 & Compressor stage 9 & 5214 & 19.15 & $1.115 * 10^{-3}$ \\
\hline 10 & Compressor stage 10 & 5214 & 19.38 & $1.115 * 10^{-3}$ \\
\hline 11 & Compressor stage 11 & 5214 & 19.66 & $1.115^{*} 10^{-3}$ \\
\hline 12 & Compressor stage 12 & 5214 & 19.94 & $1.115 * 10^{-3}$ \\
\hline 13 & Compressor stage 13 & 5214 & 20.22 & $1.115 * 10^{-3}$ \\
\hline 14 & Compressor stage 14 & 5214 & 20.55 & $1.115^{*} 10^{-3}$ \\
\hline 15 & Compressor stage 15 & 5214 & 20.87 & $1.115 * 10^{-3}$ \\
\hline 16 & Compressor stage 16 & 5214 & 21.2 & $1.115^{*} 10^{-3}$ \\
\hline 17 & Compressor stage 17 & 5214 & 21.52 & $1.115^{*} 10^{-3}$ \\
\hline 18 & Turbine stage 1 & 596783 & 32.78 & $0.364 * 10^{-2}$ \\
\hline 19 & Turbine stage 2 & 97528 & 79 & $4.1 * 10^{-2}$ \\
\hline 20 & Pinion & & 16.1 & \\
\hline 21 & Gear & & 134.78 & \\
\hline 22 & Generator & & 832.3 & \\
\hline 23 & Exciter & & 54.9 & \\
\hline
\end{tabular}

Also, the eigen vectors (natural mode shapes) corresponding only to the modal free undamped eigen values are shown in figure (10) for the unloading case and figure (11) for the loading case.

Four cases were studied, these are free undamped and damped vibration when the load is connected and disconnected from the generator for each case.

The entire results of this analysis show 42 eigen values in the form of pairs of complex conjugate. The first group of dominant values (the pairs of system modes, or the first three undamped torsional natural frequencies) of the eigen values are listed in table (5).The second group of the dominant values (first three damped torsional natural frequencies) are listed in table (6). The consideration of dominancy were based on the examining the obtained numerical values of the eigen values. It is noticed that the first three eigen values, in particular the first one, have eigen sensible differences for the cases considered. On the other hand, their corresponding natural frequencies are less than the speed of rotation when the unit is in steady operation, which suggest that their values are critical speeds and has to be carefully mounted in the running up and shutting down of the unit. The fourth eigen value and 
the rest indicates values higher than the speed of rotation, for example, $\lambda_{4}$, indicates a natural frequency of about $738(\mathrm{rad} / \mathrm{sec})$ for all the cases considered. This frequency is even higher than the second harmonics frequency of the self induced excitation that may appears in the generator with steady loading conditions, i.e., [738>2(314)] rad/sec.

Table (4): Summary of the second set of the results of twenty-two shaft segments dynamic coefficients used in the simulation

\begin{tabular}{|c|c|c|c|c|c|c|c|}
\hline No. & $\begin{array}{c}\text { Segment } \\
\text { Location } \\
\text { or } \\
\text { name }\end{array}$ & $\begin{array}{l}\text { Segment } \\
\text { stiffness }\end{array}$ & $\begin{array}{c}\begin{array}{c}\text { Material } \\
\text { damping } \\
\text { coefficient }\end{array} \\
\mathrm{C}_{\mathrm{S}}\end{array}$ & $\begin{array}{c}\begin{array}{c}\text { Bearing oil } \\
\text { damping } \\
\text { coefficient }\end{array} \\
\mathrm{C}_{B}\end{array}$ & $\begin{array}{c}\text { Electrical } \\
\text { stiffness and } \\
\text { damping } \\
\text { coefficients } \\
\mathrm{K}_{\mathrm{S}} \\
(\mathrm{N} \cdot \mathrm{m} / \mathrm{rad}) \\
\text { and } \\
\mathrm{C}_{\mathrm{e}} \\
(\mathrm{N} \cdot \mathrm{m} / \mathrm{rad} / \mathrm{s})\end{array}$ & $\begin{array}{c}\text { Gear } \\
\text { damping } \\
\text { coefficient } \\
\mathrm{C}_{\mathrm{g}} \\
\text { and sliding } \\
\text { friction } \\
\text { damping } \\
\text { coefficients } \\
\mathrm{C}_{\mathrm{Fp}} \text { and } \mathrm{C}_{\mathrm{Fg}} \\
\text { (N.m/rad/s) }\end{array}$ & $\begin{array}{c}\begin{array}{c}\text { Fluid } \\
\text { damping } \\
\text { coefficient }\end{array} \\
\mathrm{C}_{\mathrm{f}} \\
(\mathrm{N} . \mathrm{m} / \mathrm{rad} / \mathrm{s})\end{array}$ \\
\hline 1 & $1-2$ & $1.1 * 10^{11}$ & 99986 & 0.164 & \multirow{3}{*}{13237} & \multirow{3}{*}{$1.23 * 10^{11}$} & 0.5987 \\
\hline 2 & $2-3$ & $1.1 * 10^{11}$ & 93373 & 0.164 & & & 0.4394 \\
\hline 3 & $3-4$ & $1.1 * 10^{11}$ & 91173 & 0.19 & & & 0.39 \\
\hline 4 & $4-5$ & $1.1 * 10^{11}$ & 84331 & 0.19 & \multirow{3}{*}{3001} & \multirow{3}{*}{1.49} & 0.3624 \\
\hline 5 & $5-6$ & $1.1 * 10^{11}$ & 79198 & 0.425 & & & 0.296 \\
\hline 6 & $6-7$ & $1.15^{*} 10^{11}$ & 77141 & 0.425 & & & 0.3323 \\
\hline 7 & $7-8$ & $1.15^{*} 10^{11}$ & 77141 & 0.236 & & \multirow{3}{*}{2.53} & 0.3667 \\
\hline 8 & $8-9$ & $1.15 * 10^{11}$ & 77141 & 0.236 & & & 0.4032 \\
\hline 9 & $9-10$ & $1.15^{*} 10^{11}$ & 77141 & 0.486 & & & 0.4417 \\
\hline 10 & 10-11 & $1.15^{*} 10^{11}$ & 77141 & 0.486 & & & 0.4824 \\
\hline 11 & $11-12$ & $1.15^{*} 10^{11}$ & 77141 & & & & 0.5252 \\
\hline 12 & $12-13$ & $1.15^{*} 10^{11}$ & 77141 & & & & 0.5703 \\
\hline 13 & 13-14 & $1.15^{*} 10^{11}$ & 77141 & & & & 0.6176 \\
\hline 14 & 14-15 & $1.15 * 10^{11}$ & 77141 & & & & 0.6671 \\
\hline 15 & $15-16$ & $1.15^{*} 10^{11}$ & 77141 & & & & 0.719 \\
\hline 16 & 16-17 & $1.15^{*} 10^{11}$ & 77141 & & & & 0.7732 \\
\hline 17 & $17-18$ & $3.7 * 10^{8}$ & 4205 & & & & 0.8298 \\
\hline 18 & 18-19 & $1.2 * 10^{10}$ & 23142 & & & & 15.74 \\
\hline 19 & 19-pinion & $3.9 * 10^{6}$ & 431 & & & & 24.8 \\
\hline 20 & $\begin{array}{c}\text { Pinion- } \\
\text { gear }\end{array}$ & $1.23 * 10^{11}$ & 61445 & & & & \\
\hline 21 & $\begin{array}{c}\text { Gear- } \\
\text { generator }\end{array}$ & $5.25 * 10^{6}$ & 1973 & & & & \\
\hline 22 & $\begin{array}{c}\text { Generator- } \\
\text { exciter }\end{array}$ & $4.032 * 10^{7}$ & 3646 & & & & \\
\hline
\end{tabular}

Table (5): Dominant undamped torsional natural frequencies

\begin{tabular}{|c|c|}
\hline Generator condition & $\begin{array}{c}\text { Dominant modal free undamped eigen values } \\
\text { (torsional natural frequencies) } \\
(\mathrm{rad} / \mathrm{sec})\end{array}$ \\
\hline \multirow{3}{*}{ Unloading } & $\lambda_{1}=0 \pm 8.0053 \mathrm{i}$ \\
\hline & $\lambda_{2}=0 \pm 90.468 \mathrm{i}$ \\
\hline & $\lambda_{3}=0 \pm 285.83 \mathrm{i}$ \\
\hline \multirow{3}{*}{ Loading } & $\lambda_{1}=0 \pm 13.116 \mathrm{i}$ \\
\hline & $\lambda_{2}=0 \pm 90.936 \mathrm{i}$ \\
\hline & $\lambda_{3}=0 \pm 285.84 i$ \\
\hline
\end{tabular}


Table (6): Dominant damped torsional natural frequencies

\begin{tabular}{|c|c|c|}
\hline $\begin{array}{l}\text { Generator } \\
\text { condition }\end{array}$ & $\begin{array}{c}\text { Dominant modal free damped eigen } \\
\text { values (torsional damped natural } \\
\text { frequencies) }(\mathrm{rad} / \mathrm{sec})\end{array}$ & $\begin{array}{l}\text { Modal damping } \\
\text { values } \\
(\zeta)\end{array}$ \\
\hline \multirow{3}{*}{ Unloading } & $\lambda_{1}=-6.8088 \pm 4.3700 \mathrm{i}$ & $\mathbf{0 . 8 4 0 0}$ \\
\hline & $\lambda_{2}=-10.846 \pm 88.932 \mathrm{i}$ & 0.1210 \\
\hline & $\lambda_{3}=-10.267 \pm 285.60 \mathrm{i}$ & 0.0360 \\
\hline \multirow{3}{*}{ Loading } & $\lambda_{1}=-6.9639 \pm 11.289 \mathrm{i}$ & 0.5250 \\
\hline & $\lambda_{2}=-10.960 \pm 89.399 i$ & 0.1217 \\
\hline & $\lambda_{3}=-10.267 \pm 285.61 \mathrm{i}$ & 0.0359 \\
\hline
\end{tabular}

\section{Discussion and Conclusions}

\section{Stiffness Coefficients}

It is known that the values of shaft stiffness $\left(\mathrm{K}_{\mathrm{S}}\right)$ depend naturally on segment shaft diameter and length (equation 49). This interpret the equivalent different values of $\left(\mathrm{K}_{\mathrm{S}}\right)$ due to different shaft steps of different length and diameter.

The value of gear stiffness $\left(\mathrm{K}_{\mathrm{g}}\right)$ mainly depends upon face width and average base radius of the two mating gears considering the same material for pinion and gear. It's estimated value is seems to be of the same order of shaft stiffness $\left(\mathrm{K}_{\mathrm{S}}\right)$.

On the other hand, the electrical stiffness $\left(\mathrm{K}_{\mathrm{e}}\right)$ or as sometimes so-called synchronizing torque depends, purely, on electrical parameters, namely, terminal voltage, excitation voltage, synchronous reactance and rotational speed of the generator. It's value is relatively small compared with the mechanical stiffness $\mathrm{K}_{\mathrm{e}}$. The effect of electrical stiffness is introduced in system equations only when the generator is connected with electrical network, i.e., when the generator is in operation.

\section{Damping Coefficients}

Damping means dissipation of energy, but this concept is slightly different depending on whether the damping is absolute or relative. In other words, mass/frame motion or mass/mass motion.

Specifically, the effect of absolute damping has a permanent nature, or in other words, the energy dissipation in the form of friction regardless of system operation whether in steady or transient cases. Therefore, the mechanical efficiency is directly affected by absolute damping as in bearing oil film damping, electrical damping and fluid damping. This interpret why the absolute damping has little magnitudes in comparison with the values of relative damping because any of these magnitudes will influence directly the power generation efficiency.

The relative damping has no effect when the system is in steady-state operation, and seems to be very effective when the system pass or exposed to any type of transient cases, 
such as loading or unloading and in the case of faults. The main types of the relative damping are the material damping, gear mesh damping and sliding friction of gear system damping.

\section{System Eigen Values (Torsional Natural Frequencies) and Eigen Vectors (Mode Shapes)}

\section{System Eigen Values}

Generally, it can be said that the eigen values of the system in operation (load is connected) becomes larger than the eigen values of the inoperative system (load is disconnected), especially for the three modal dominant eigen values. Loading connection means the addition of electrical stiffness $\left(\mathrm{K}_{\mathrm{e}}\right)$ to the model, which represents the conjunction between the turbo-generator unit and the network. This interprets the change in eigen values.

Table (5) shows the first three torsional natural frequencies for a conservative system. They liable to be indirectly excited by unbalance or directly torque changes (e.g. dynamic torques ) as the unit is running up from standstill to around $314.16 \mathrm{rad} / \mathrm{sec}(3000 \mathrm{rpm})$ which represent the operation speed of the generator.

Table (6) shows the first three torsional damped frequencies for a non-conservative system. Here, free vibration decays due to damping action. Decaying is an indication of system stability. Generally the conclusion which can be drawn is that the eigen values of the system are decreasing due to damping action, and increasing when the system is in operation under loading conditions.

\section{System Eigen Vectors (Mode Shapes)}

The mode shapes show the relative angular displacement of each lumped mass including blades with respect to angular displacement of lumped mass number one (stage number one of the compressor). For the disconnected load condition (figure 10), two rotor nodes observed for third mode $\left(\omega_{1}=285.83 \mathrm{rad} / \mathrm{sec}\right)$. On the other hand, one node is observed only for the intermediate mode $\left(\omega_{2}=90.468 \mathrm{rad} / \mathrm{sec}\right)$. The first mode has no apparent nodes $\left(\omega_{1}=8.0053\right.$ $\mathrm{rad} / \mathrm{sec}$ ), this means that the whole rotor moves as a rigid body because there are no nodes and hence no relative displacement between lumped masses. It may be noticed that high modal damping are relatively for the first and second mode in the two cases of loading and unloading condition when compared to that of the third mode $(\zeta=0.036)$. This suggest that the prime torsional vibration appears for this mode. Existence of rotor nodes is very beneficial because rotor nodes mean no torsional vibration at node location and hence no relative angular displacement. Determination of these rotor nodes locations gives a good guidance for the designers to select the best locations to install specific parts along the rotor length to avoid harmful torsional vibrations. The important observation here is that most nodes locates directly on the quill shaft position (between gear and generator or 40 and 41 on the abscissa of figure (10) or (11)) or in the vicinity of it. Actually, this shaft is designed and manufactured from a material possesses high torsional flexibility to be able to absorb harmful torsional vibrations.

The results, shown in figure (10) represent the load disconnection case. The mode shapes in figure (11) illustrate the relative angular displacements of all lumped masses where 
the load is in connection. All mode shapes in the load connected condition and disconnected are approximately similar.

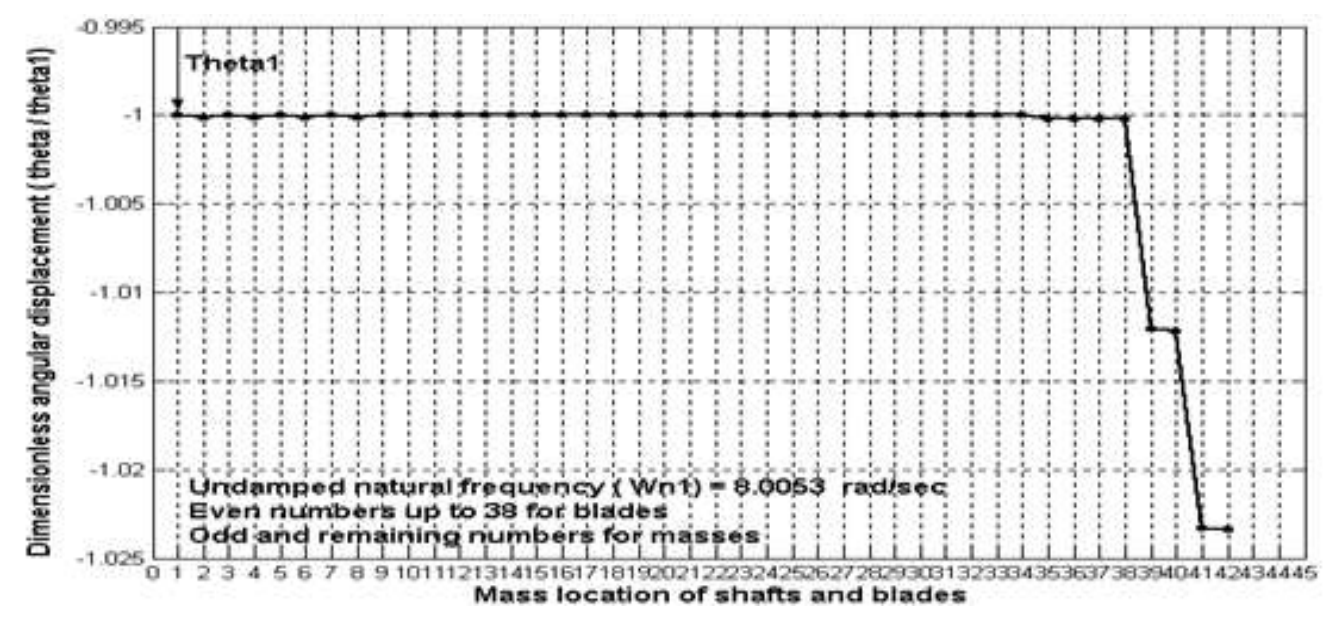

(c) Third mode (no nodes)

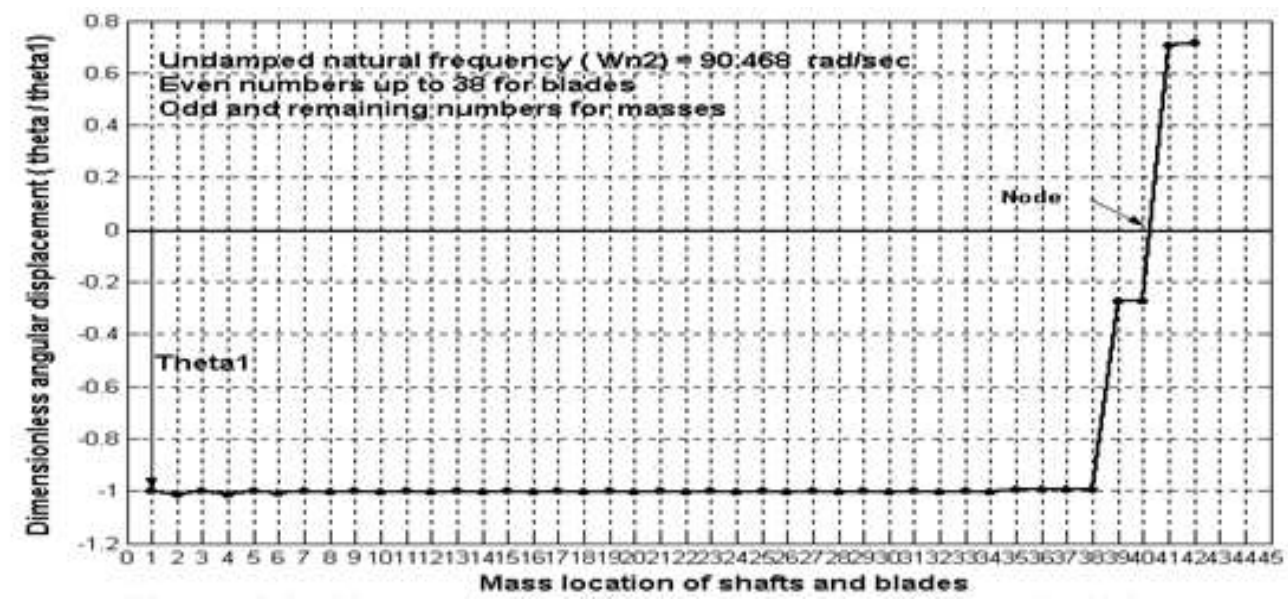

(b) Second mode-intermediate mode (1-node)

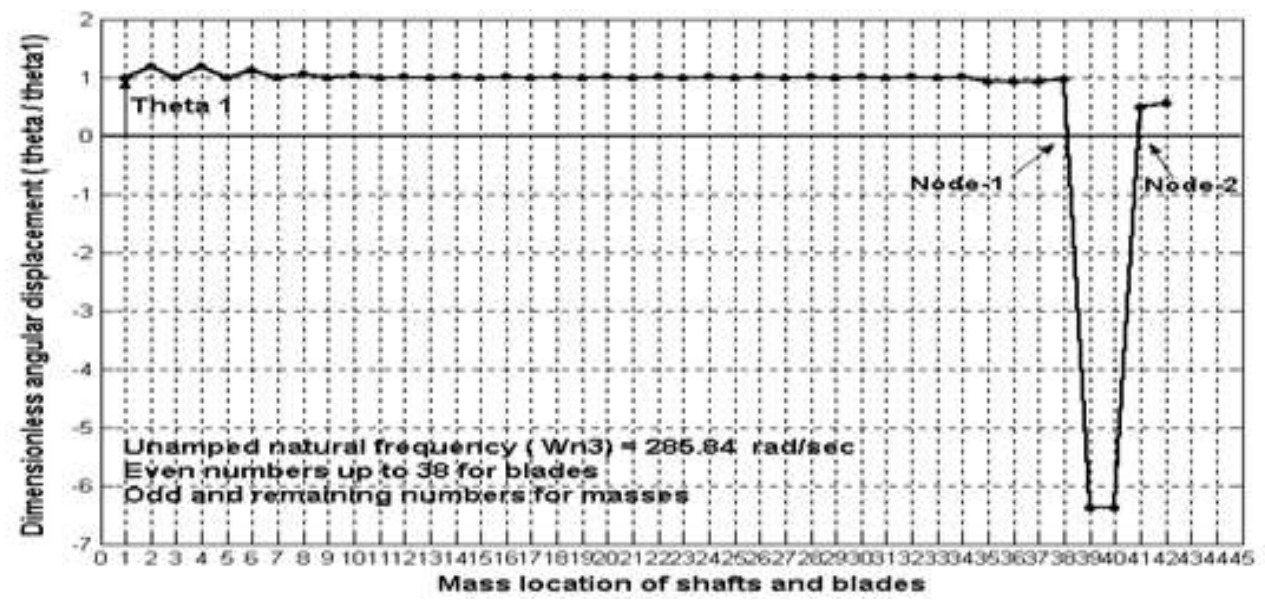

(a) First mode (2-nodes)

Figure (10): Mode shapes (load is disconnected) 

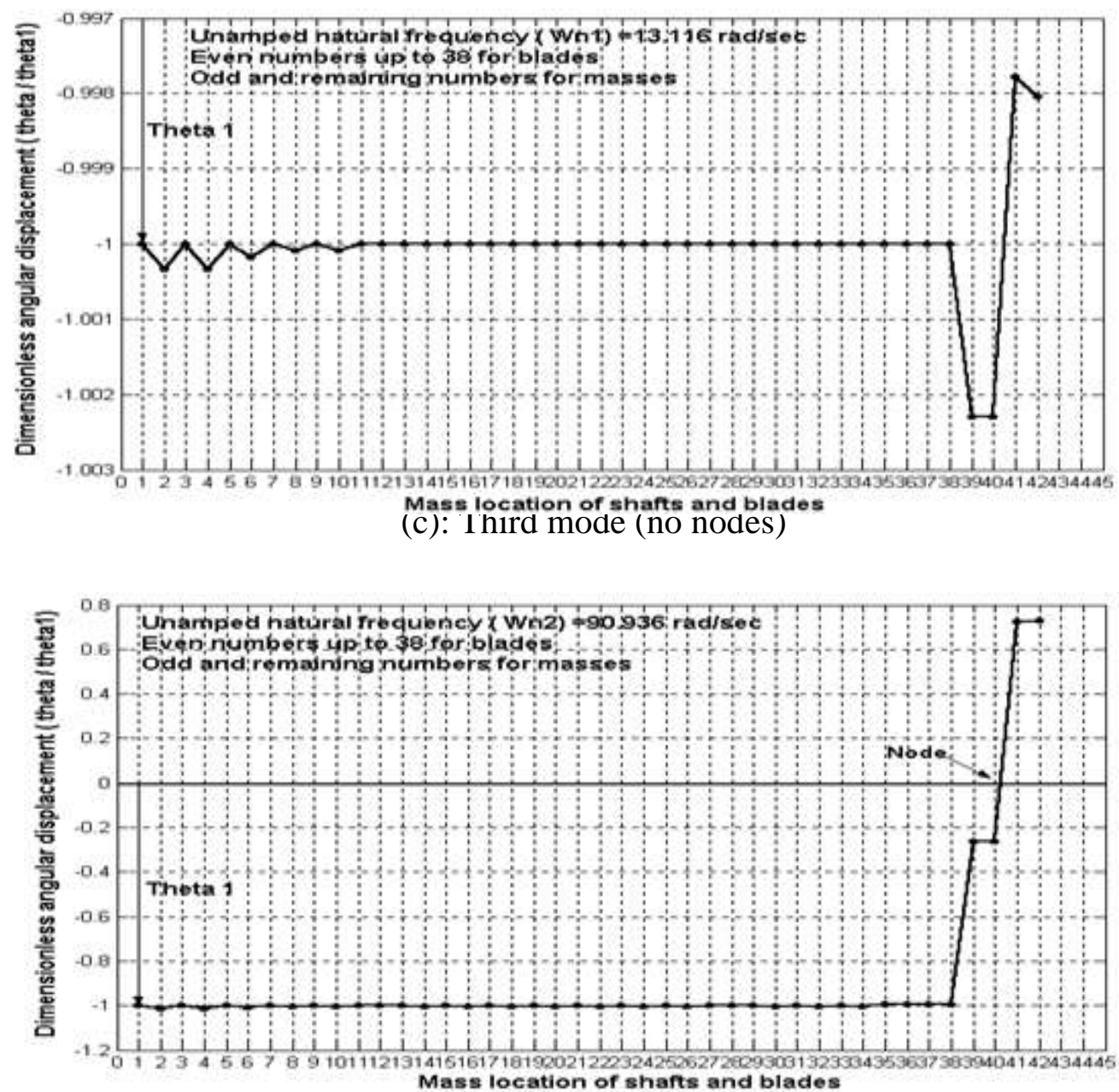

(b): Second mode-intermediate mode (1-node)

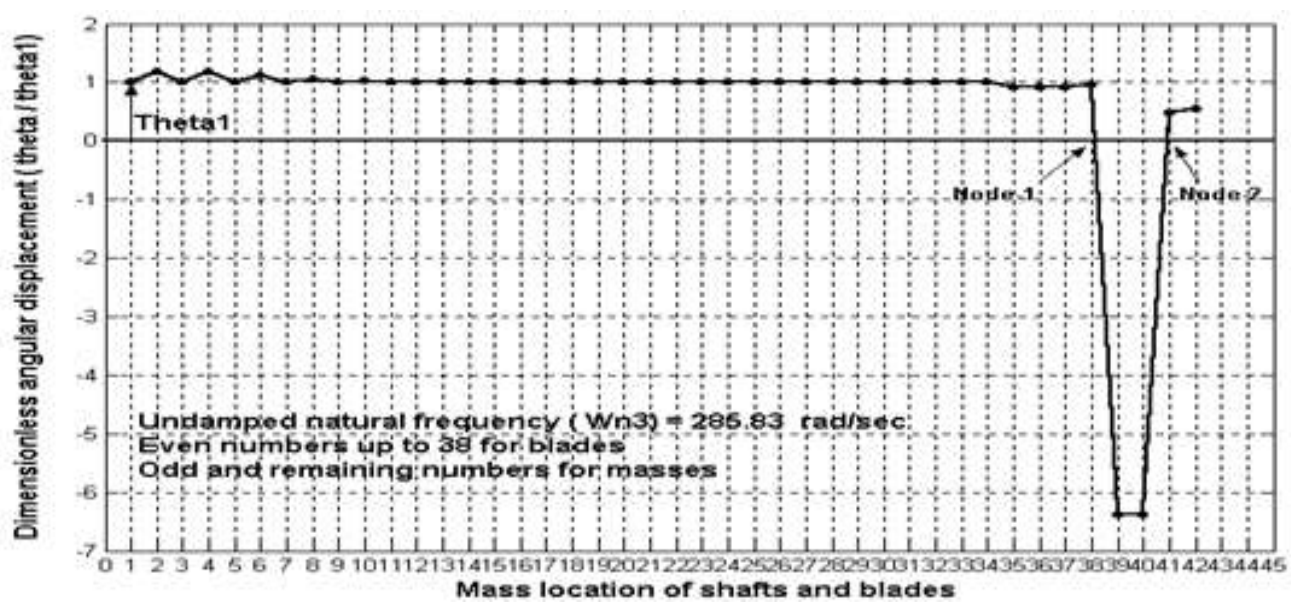

(a): First mode (2-nodes)

Figure (11): Mode shapes (load is connected) 


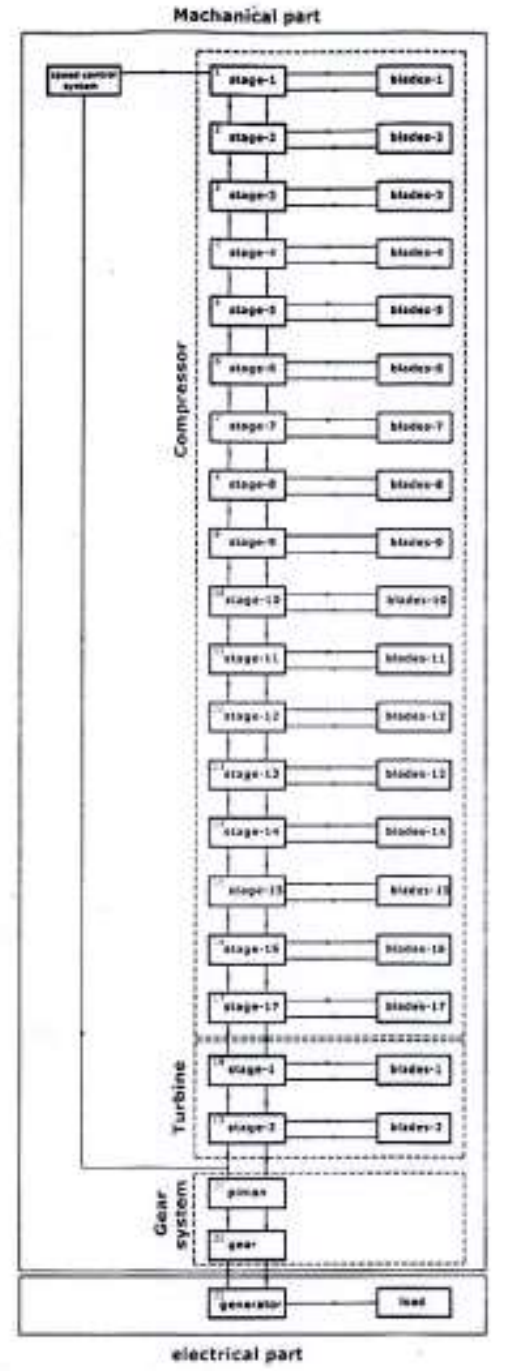

Figure (12): Overall block diagram of the simulated power system

\section{References}

1. IEEE Working Group Interm Report, Effects of Switching Network Disturbances on Turbine Generator Shaft Systems, IEEE Transactions on Power Systems, Vol. PAS-101, No.9, September, 1982.

2. Hammons T. J. , Stressing of Large Turbine- generators at Shaft Couplings and LP Turbine Final Stage Blade Roots Following Clearance of Grid System Fault and Fault Synchronization, IEEE Transactions on Power Apparatus and Systems, Vol. PAS-99, No.4, July/August, 1980.

3. Hammons T. J., Accumulative Fatigue Life Expenditure of Turbine-generator Shafts Following Worst-case System Disturbances, IEEE Transactions on Power Apparatus and System, Vol. PAS-101, No.7, July, 1982.

4. Tsai J. I., Lin C.H. and Tsao T. P., Assessment of Long-Term Life Expenditure for Steam Turbine Shafts Due to Non characteristic Subharmonic Currents in Asynchronous Links, IEEE Transactions on Power Systems, Vol.19, No.1, February 2004.

5. Norton R. L., Design of Machinery: An introduction to the Synthesis and Analysis of Mechanisms and Machines, McGraw-Hill companies, 2001. 
6. James M. L., Smith G. M. , Wolford J. C. and Whaley P. W., Vibration of Mechanical and Structural Systems, 1989.

7. Yang D. C. H. and Sun Z. S. , A Rotary Model for Spur Gear Dynamics, ASME Journal of Mechanisms, Transactions and Automation in Design, Vol.107, PP : 529-535, December, 1985.

8. Lin H. H. , Huston R. L. and Coy J. J. , On Dynamic Loads in Parallel Shaft Transmissions : Part-II Modeling and Analysis, ASME Journal of Mechanisms, Transactions and Automation in Design, Vol. 110, PP: 226-229, June 1988.

9. Sen S. K. , Rotating Electrical Machinery, Kanna Publishers, 1975.

10. Nasar S. A. and Unnewehr L. E., Electromechanics and Electric Machines, John Wiley and Sons, Inc., 1983.

11. Wilson W. K., Practical Solution of Torsional Vibration Problems, Vol.2, Amplitude Calculations, Chapman and Hall Ltd. London, 1963.

12. Hahn W. F. , Study on Instantaneous Load to Which Gear Teeth are Subjected, Ph.D. Dissertation, University of Illinois, 1969.

13. Hunt K. H. and Crossley F. R. E., Coefficient of Restitution Interpreted as Damping in Vibroimpact, ASME Journal of Applied Mechanics, Vol. 97, pp.440-445, June 1975.

14. Kasuba R. and Evans J.W., An Extended Model for Determining Dynamic Loads in Spur Gearing, ASME Journal of Mechanical Design, Vol. ,pp.398-409, April, 1981.

15. Wang K. L. and Cheng H. S., A Numerical Solution to the Dynamic Load, Film Thickness, and Surface Temperature in Spur Gears, ASME Journal of Mechanical Design, Vol. 2 , pp.177-187, January, 1981.

16. Velex P. and Cahouet V., Experimental and Numerical Investigations on the Influence of Tooth Friction in Spur and Helical Gear Dynamics, Proceedings of the 2000 ASME Design Engineering Technical Conference DETC2000/PTG-14430,1-10, Baltimore, U.S.A, 2000.

17. Martin K. F., The Efficiency of Involute Spur Gears, Transactions of the American Society of Mechanical Engineers, paper no.80-C2/DET, 1980.

18. Vaishya M. and Singh R., Sliding Friction-Induced Non-Linearity and Parametric Effects in Gear Dynamics, Journal of Sound and Vibration, 248(4), 671-694, 2001.

19. Iida H., Tamura A. and Yam ada Y., Vibrational Characteristics of Friction Between Gear

Teeth, Bulletin of the Japanese Society of Mechanical Engineers 28, 1512-1519, 1985.

20. Buckingham E., Analytical Mechanics of Gears, Dover Publications, Inc., 1963.

21. Niemann G., Machine Elements, Design and Calculations in Mechanical Engineering, Vol.1, Allied Publishers Private Limited, 1980.

22. Shiply E. E., Efficiency of Gear Trains, Production Engineering, August 4, Vol.29, No.31, 1958.

23. Cameron A., The Principles of Lubrication, Longmans Green and Co. LTD, 1966.

24. Cameron A., Basic Lubrication Theory, Longman Group Ltd., 1971.

25. Armstrong E. K. and Williams D. D., Some Intake Flow Maldistribution Effects on Compressor Rotor Blade Vibration, Journal of Sound and Vibration 3(3), 340-354, 1966. 